Title:

\title{
Differences in perceptual memory influence generalization patterns
}

Ann-Kathrin Zenses ${ }^{a}$, Jessica C. Lee ${ }^{b}$, Valérie Plaisance ${ }^{a}$ and Jonas Zaman ${ }^{a, c}$

a Center for the Psychology of Learning and Experimental Psychopathology, Faculty of Psychology and Educational Sciences, KU Leuven, Tiensestraat 102, Box 3712, 3000 Leuven, Belgium

b University of New South Wales, Sydney, NSW 2052, Australia

c Health Psychology, Faculty of Psychology and Educational Sciences, KU Leuven, Tiensestraat 102, box 3726, 3000 Leuven, Belgium

Number of figures: 5

Number of Tables: 0

Word count: 5642

Supplemental information: yes

Corresponding author:

Jonas Zaman, PhD

Health psychology

Tiensestraat 102 - bus 3726

3000 Leuven

Tel. +3216373197

Fax +32 16326144

E-mail: Jonas.zaman@kuleuven.be

Institutional URL : https://ppw.kuleuven.be/ogp 


\section{Abstract}

Although memory of past experiences is crucial for the ability to transfer knowledge to new situations, surprisingly little research has directly investigated the relationship between memory and generalization. The present study sought to investigate how the perceptual memory of a trained stimulus influences generalization to similar stimuli. Forty participants underwent a fear conditioning procedure on Day 1, and separate memory recall and generalization tests on Day 2. We focused on two aspects of perceptual memory: namely memory bias (i.e., over- or underestimating stimulus features) and uncertainty. We found that memory bias influenced the pattern of generalized selfreported (expectancy ratings) and psychophysiological responses (fear-potentiated startle responses). Memory uncertainty was measured in two ways: self-reported uncertainty ratings and variability in stimulus recall. We demonstrated that higher levels of self-reported memory uncertainty led to a broadening of the US expectancy generalization gradient, whereas an effect of variability in memory recall on generalization was only found for fear-potentiated startle responses. Taken together, our findings suggest that memory is an important determinant of generalized behavior and illustrate the need to account for these interindividual differences in perceptual memory when examining the generalization of learned responses.

Keywords: Memory; Recall; Fear conditioning; Generalization; Uncertainty 


\section{Intro}

One of the indispensable tools that we have at our disposal is the ability to use past experiences to guide current thoughts and actions in novel situations. Numerous studies have demonstrated that the average strength (or probability) of a previously trained response wanes as a function of the physical difference between test and training stimuli, yielding a response gradient (Ghirlanda \& Enquist, 2003; Mednick \& Freedman, 1960).

Given that we do not have direct access to the physical properties of the stimuli, but must rely on the input from senses, theories of generalization capture physical differences between stimuli as overlap between activated representational units (Blough, 1975; Ghirlanda \& Enquist, 2007; McLaren \& Mackintosh, 2002) or distance between stimulus representations in a perceptual or psychological space (Jäkel, Schölkopf, \& Wichmann, 2007, 2008; Shepard, 1987; Shepard, 1958). A common assumption in these theories is that the representation of the trained stimulus is veridical. However, it is possible that there are individual differences in participants' memory of the stimulus. The degree of similarity, a crucial determinant of generalization, would therefore depend on how well participants could remember the trained stimulus. It follows that perceptual memory, in addition to other processes, plays an important role in generalization. It has been even suggested that memory instability is the pathway through which generalization originates (Robertson, 2018). Related to this, the forgetting of stimulus features due to the passage of time has been suggested to contribute to a widening of generalization gradients (Jasnow, Cullen, \& Riccio, 2012; Riccio, Ackil, \& Burch-Vernon, 1992; Riccio, Richardson, \& Ebner, 1984). This proposal is based on animal research where longer delays between learning and testing flattened generalization gradients, while response strength did not fade (Perkins \& Weyant, 1958; Thomas \& Burr, 1969; Riccio et al., 1984). In those studies, memory effects were inferred from the widening of generalization gradients of a trained response but without any separate assessment of memory. Other studies have demonstrated that the variability of a memory representation increases with longer retention intervals (Huang \& Sekuler, 2010). In another study, new items related to a previous threat paired category were more often falsely recognized compared to items related to a safe category (Starita, Kroes, Davachi, Phelps, \& Dunsmoor, 2019). Yet, it remains unclear how such a memory bias relates to threat generalization as only response accuracies during a recognition task were recorded. Thus, as none of these studies included assessment of memory and generalization in separate tasks, it remains to be empirically demonstrated whether uncertainty or bias in memory is a determinant of generalization.

One way to quantify individual differences in perceptual memory is to ask participants to recall certain physical characteristics of a stimulus during an adjustment task. In this task, subjects have to adjust 
the features of a stimulus so that it matches their representation in memory. Deviations from the actual stimulus tend to follow a normal distribution, with a mean and standard deviation describing the bias and variability of memory respectively (Huang \& Sekuler, 2010). The perceptual memory of a stimulus, when thought of as a probability distribution (Riccio et al., 1984), may influence future behavior in a twofold manner. Deviations of the distribution's mean from the actual stimulus, reflective of a memory bias, could cause asymmetries in the response gradient. Indirect support for this comes from a study by Dunsmoor et al. (2009) where the test stimulus that elicited the strongest fear response was also most often identified as the trained stimulus during a recognition task (Dunsmoor, Mitroff, \& LaBar, 2009). Two recent studies that combined a two alternative forced-choice (2AFC) categorization task with a generalization task found that shifts in the probability of incorrectly categorizing test stimuli as the trained stimulus (potentially reflecting a memory bias) were associated with parallel shifts in the generalization gradient with stronger conditioned responses in the direction of the memory (or perceptual) bias (Struyf, Zaman, Hermans, \& Vervliet, 2017; in Supplementary Information [SI] of Zaman, Struyf, Ceulemans, Beckers, \& Vervliet, 2019). In those studies, generalization was tested immediately after training. With a longer delay between training and test, the influence of these memory biases on generalization may be even stronger.

The width of the perceptual memory distribution, reflective of its precision (or uncertainty), has been proposed to increase the breadth of generalization (Jasnow et al., 2012; Riccio et al., 1992, 1984). A wider distribution should lead to more generalization because the overlap in probability distributions between the perceived stimulus features and recalled stimulus features would be larger than with a narrower distribution (Blough, 1975; Ghirlanda \& Enquist, 2007). Finally, according to Bayes' rule, one would expect the effect of a bias to decrease as the width of the memory distribution (i.e., uncertainty about the remembered stimulus features) increases (Zaman, Vanpaemel, Aelbrecht, Tuerlinckx, \& Vlaeyen, 2017).

The present study aimed to determine the effect of perceptual memory bias and uncertainty on the generalization of an acquired fear response, across a range of differently sized circles (which have been used successfully to yield symmetrical generalization gradients; Zaman, Ceulemans, Hermans, \& Beckers, 2019; Zaman, Struyf, et al., 2019). We used a two-day simple Pavlovian conditioning procedure with an fear acquisition on the first day, and a recall and a generalization task on the second day. In the acquisition phase, the image of a circle [conditioned stimulus (CS)] was repeatedly paired with a painful electrocutaneous stimulus [unconditioned stimulus (US)]. Twenty-four hours later, recall of the circle size was assessed, using an adjustment task, in addition to memory uncertainty using self-report. Afterwards, the extent to which a range of differently sized circles elicited the trained fear response (indicated by fear-potentiated startle responses and US expectancy ratings) was tested. 
Crucially, the recall phase occurred before the generalization test. That is, participants had to freely recall the size of the circle from their memory without being exposed to any stimuli, as would be the case if the recall phase had occurred after the generalization test or if we had instead used a recognition task to assess memory.

\section{Method and Material}

\subsection{Preregistration}

The study has been preregistered on the Open Science Framework (OSF) (https://osf.io/qw4ke). Deviations from the preregistered protocol and additional, exploratory analyses are reported as such. The complete data are publicly available on the OSF (https://osf.io/42x9y/).

\subsection{Participants}

Forty-one healthy volunteers participated in the study, of which 40 completed both parts and were included in the analyses [30 females $(75 \%)$, mean age: $21.68(S D=2.02)]$. The recruitment of participants took place through local advertisement boards and social media. As a compensation for their participation in both parts of the study, they could choose between 20 euros or partial course credits. Exclusion criteria, based on self-report, were cardiac or cardiovascular disorders, lung disease or breathing problems, neurological disorders, other severe medical conditions, (a history of) psychiatric disorders, acute or chronic pain, pregnancy, hearing difficulties, recommendation from a general practitioner to avoid stressful situations, any type of electronic implant, use of recreational drugs, recovering from severe trauma, taking medication that affects the central nervous system, being below eighteen or above fifty years of age and inadequate comprehension of the Dutch language. The study was approved by the social and societal ethics committee (SMEC) of the KU Leuven, Belgium (G201610 641). All participants provided their written informed consent.

\subsection{Electrocutaneous stimulation}

Electrocutaneous stimuli were delivered through an electrocutaneous stimulation device (Constant Current Stimulator, model DS7), attached to the non-dominant wrist. The intensity of the stimulation was determined, for each individual, at the beginning of Day 1 and Day 2 by using the Ascending Method of Limits approach (Yarnitsky, Sprecher, Zaslansky, \& Hemli, 1995). Participants were instructed that the stimulus should be painful but tolerable. Each stimulus was rated on a visual analog scale (VAS; 0 = no pain, 10 = most imaginable pain). Stimulation levels gradually increased until a VAS score of eight was obtained or the participant indicated that pain tolerance was reached. The average 
stimulation intensity was $20.48 \mathrm{~mA}(S D=8.85)$ on Day 1 and increased to $24.65 \mathrm{~mA}(S D=11.94)$ on Day $2[t(39)=4.646, p<.001]$.

\subsection{Visual stimuli}

Seven differently sized circles were created as white outlines against a black background (S1-S7, varying diameters from 7.72 to $12.56 \mathrm{~cm}$ with steps of $0.807 \mathrm{~cm}$ ). Across a dimension of increasing diameter, the middle circle served as CS (diameter $=10.14 \mathrm{~cm}$; S4), the others as generalization stimuli. Two rectangles $(8.79 \times 2.83 \mathrm{~cm}$ and $2.93 \times 0.94 \mathrm{~mm})$ were used as stimuli during the practice trials.

\subsection{Eye blink startle responses}

Orbicularis oculi electromyographic (EMG) activity was recorded as index of covert defensive mobilization (Bradley \& Lang, 2000; Lang, Davis, \& Ohman, 2000) by using three trimmed disposable $\mathrm{Ag} / \mathrm{AgCl}$ electrodes (H124SG, $24 \mathrm{~mm}$, Covidien $@$, UK). Two of them were attached under the left eye and one on the forehead, according to the guidelines of Blumenthal and colleagues (Blumenthal et al., 2005). Before electrode attachment, the skin was abraded with a mild abrasive cream (Inecto). Startle eye blink responding was triggered by a 50 -ms burst of white noise (called the startle probe) with a peak of $105 \mathrm{~dB}$ presented binaurally through headphones (Sennheiser, HD418). The raw signal was passed through a $13 \mathrm{~Hz}$ high pass and $500 \mathrm{~Hz}$ low pass bandpass filter (v75-04, Coulbourn isolated bioamplifier@, USA), rectified and smoothed with a time constant of $20 \mathrm{~ms}$ (V76-24, Coulbourn Integrator(C, USA). EMG was sampled at $1000 \mathrm{~Hz}$ and recorded continuously. Time intervals of 1000 ms prior to probe onset until $1000 \mathrm{~ms}$ after probe onset were used to visually inspect (offline) the EMG signal for artifacts and non-responses. Rejection criteria were spontaneous blinks in the $200 \mathrm{~ms}$ interval preceding probe onset or excessive noise in the EMG signal. Startle eye blink amplitudes were computed by subtracting the mean baseline value $(0-20 \mathrm{~ms}$ after probe onset) from the peak value found in the 21-175 ms time window after startle probe onset. To reduce inter-individual variation, startle amplitudes were transformed into $t$-scores. Final startle amplitudes were expressed relative to baseline (noise alone trials), computed as the difference between the startle amplitude on a given trial from the averaged startle amplitude of noise alone trials. Due to excessive noise, $14.25 \%$ of the startle recording were rejected ( 342 of 2400 trials). If more than $50 \%$ of the startle trials were non-responses for a given participant, this participant was deemed a non-responder and their data omitted from the startle analyses $(n=1)$.

\subsection{Protocol}

\subsubsection{Day 1}


Participants were invited twice to the laboratory during a two-day protocol with exactly 24 hours between both sessions. On Day 1, participants gave informed consent after receiving written and oral information. The first day comprised a calibration, practice, startle probe habituation, habituation and acquisition phase (Fig. 1A). After determining the intensity of the US, participants were familiarized with the trial timings and the task, during two practice trials. Each trial commenced with the presentation of a visual stimulus (i.e., one of the rectangles) simultaneously with the size-VAS (at the bottom of the screen; range: 0 - 200 with $\mathrm{mm}$ as unit) on which participants indicated the estimated diameter of the presented stimulus (Fig. 1B) ${ }^{1}$. No feedback was provided about the accuracy of their response. After $5 \mathrm{~s}$, the size-VAS disappeared and was replaced with the expectancy-VAS (at the bottom of the screen) for another $5 \mathrm{~s}$ during which the visual stimulus remained present. On this expectancy-VAS, subjects indicated to what extent they expected the US to occur $(0=$ never, $10=$ always).

Next, ten startle probes were presented with a variable interval between probes (average duration 20 s) while a fixation cross was presented on screen (startle habituation phase). The habituation phase consisted of six trials during which the CS was presented simultaneously with the size-VAS on which participants indicated the estimated diameter of the presented circle (Fig. 1B). After $5 \mathrm{~s}$, the size-VAS disappeared and was replaced with the expectancy-VAS. Ten seconds after CS onset both the CS and the expectancy-VAS disappeared. Trials were separated by the presentation of a fixation cross with a variable duration between 8 and $12 \mathrm{~s}$. There were no startle probe and US presentations during the habituation phase.

The acquisition phase started immediately after the habituation phase, and consisted of 20 CS trials and 2 noise alone trials. The trial structure was identical to the training phase with the only exception that the US and/or a startle probe could occur on certain trials (Fig. 1B). More specifically, in $80 \%$ of the trials the CS was followed by the US, which was administered at CS and expectancy-VAS offset. A startle probe was presented in $40 \%$ of the trials during CS presentation (random between 5 and $9 \mathrm{~s}$ after CS onset). During noise alone trials, the fixation cross remained on the screen and a startle probe was presented randomly between 4 and $8 \mathrm{~s}$ after fixation cross onset. Finally, participants completed the State-Trait Anxiety Inventory (STAI-T; Spielberger, Gorsuch, Lushene, Vagg, \& Jacobs, 1983) and the Groningen Sleep Quality Scale (Meijman, T. F., de Vries-Griever, De Vries, \& Kampman, 1988) to measure trait anxiety and sleep quality during the previous night, respectively. ${ }^{2}$

\footnotetext{
${ }^{1}$ This measure was included for exploratory analyses (see SI).

${ }^{2}$ Due to practical reasons, the Pittsburgh Sleep Quality Index (PSQI;Buysse, Reynolds, Monk, Berman, \& Kupfer, 1989) could not be administered, although this was included in the preregistration.
} 


\subsubsection{Day 2}

Day 2 consisted of a calibration, recall, startle probe habituation and generalization phase (Fig. 1C). The calibration procedure was identical on both days. The recall phase included 10 trials in which participants were instructed to recreate the size of the circle that was presented on Day 1 (i.e., the CS). They could do so by pressing the left and right key on the keyboard to decrease and increase the diameter of a circle (in steps of $0.2929 \mathrm{~mm}$ ) that started as a small dot, located at the center of the screen (Fig. 1D). Participants confirmed the recreated circle with a button press. While the recreated circle remained on screen, they indicated how certain they were about the correctness of their response $(0=$ not certain, $10=$ very certain). Finally, they reported retrospective US expectancies (i.e., the likelihood that this circle was followed by the US during the acquisition phase) on a scale ranging from 0 (never) to 10 (always). Between trials, a fixation cross was presented with a variable duration between 8 and $12 \mathrm{~s}$. At the end of this phase, participants were asked to indicate how many different circles they saw on Day 1. The generalization phase consisted of 5 blocks, separated by 1-min breaks, each block including 5 CS trials, 2 noise alone trials and 12 GS trials (two per GS type). Stimulus order within each block was random. Trial structure (including the reinforcement rate of $80 \%$ for CS trials) was identical to the acquisition phase on Day 1 (Fig. 1E). GS trials were identical to CS trials with the only exception that the GS was never followed by the US. A startle probe was presented in $47 \%$ of all trials, occurring randomly between 5 and $9 \mathrm{~s}$ after stimulus onset.

Before participants were debriefed, they completed the Groningen Sleep Quality Scale (Meijman, T. F. et al., 1988), which assessed participants' sleep quality of the previous night.

Day 1

(A)

\begin{tabular}{|c|c|c|c|c|}
\hline $\begin{array}{c}\text { US } \\
\text { calibration }\end{array}$ & Practice & $\begin{array}{c}\text { Startle Probe } \\
\text { habituation }\end{array}$ & Habituation & Acquisition \\
\hline
\end{tabular}

(B)

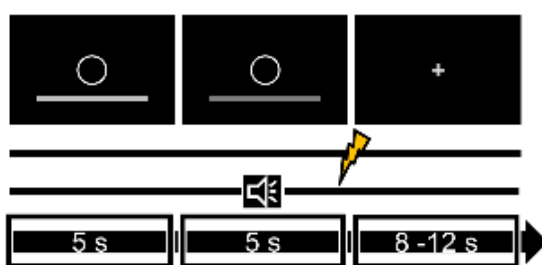

(C)

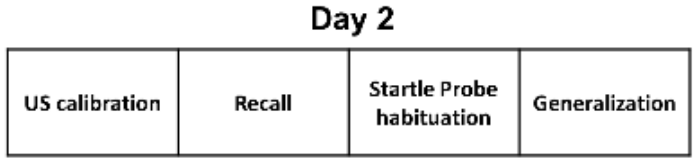

(D)

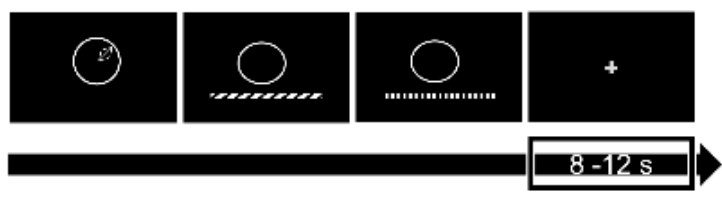

(E)

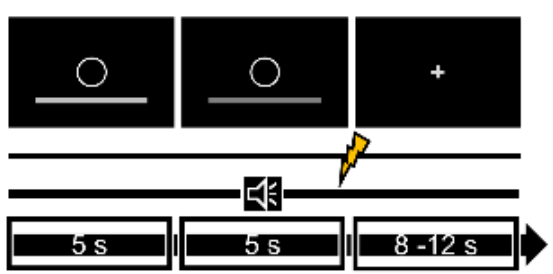


Fig. 1. (A) Overview of the different phases on Day 1. (B) Structure of a trial during the acquisition phase on Day 1. (C) Overview of the different phases on Day 2. (D) Structure of a trial during the recall phase on Day 2. (E) Structure of a trial during the generalization phase on Day 2. The trial structure was identical to $(B)$ with the only exception that generalization stimulus presentations could also occur instead of CS presentations. CS = conditioned stimulus.

\subsection{Data analyses}

All analyses were performed using SPSS 20. Learning on Day 1 was assessed using mixed effects models. For the US expectancy ratings, an increase across trials was tested (Fixed effect: intercept + trial, Random effect: subject-dependent intercept). Startle eye blink responses were expressed as difference scores from baseline responding (i.e., noise alone trials) and were tested across all trials (Fixed effect: intercept, Random effect: subject-dependent intercept). Startle eye blink difference scores $>0$ are indicative of startle potentiation (i.e., stronger startle responding during the stimulus trials than during the noise alone trials).

On Day 2, the data from the recall phase and generalization phase were analyzed separately. Potential changes across recall trials were assessed for all three measures: recalled CS size, recall (un)certainty and retrospective US expectancy ratings (Fixed effect: intercept + trial, Random effect: subjectdependent intercept). For the generalization data (US expectancy ratings and startle eye blink responses), we first assessed whether a gradient was observed across the stimulus dimension (Fixed effect: intercept + stimulus + trial, Random effect: subject-dependent intercept).

Next, the influence of memory bias and uncertainty on the gradient was assessed in separate models. Memory bias was operationalized as participants' averaged recalled CS size $\left(\mu_{r}\right)$ minus the actual CS size (memory bias $=\mu_{r}-101.41$, see Fig. $\left.3 C\right)$ (Fixed effect: intercept + trial + stimulus + memory bias + memory bias $\times$ stimulus, Random effect: subject-dependent intercept) ${ }^{3}$. Two indices for memory uncertainty were computed: mean self-reported recall uncertainty ( $\mu_{u}$ Fig. $\left.3 D\right)$, and a more implicit index, the amount of variation in recalled size across all recall trials (standard deviation, $\sigma_{r}$ ) (Fixed effect: intercept + trial + stimulus + memory uncertainty + memory uncertainty $\times$ stimulus, Random effect: subject-dependent intercept). Finally, we investigated whether the influence of memory bias was dependent upon memory uncertainty (Fixed effect: intercept + trial + stimulus + memory uncertainty + memory bias + memory uncertainty $\times$ stimulus + memory bias $\times$ stimulus + memory bias $\times$ memory uncertainty $\times$ stimulus, Random effect: subject-dependent intercept). All predictors were entered into the model as continuous predictors apart from stimulus, which was a categorical

\footnotetext{
${ }^{3}$ For ease of interpretation, a difference score between mean recalled CS size and physical CS size was adopted for memory bias rather than what was preregistered (i.e., mean recalled CS size).
} 
predictor $^{4}$. Degrees of freedom were estimated using the Satterthwaite approximation (Satterthwaite, 1946) and were rounded off to the closest integer.

We report the primary analyses relevant to our hypotheses. Parameter estimates and $95 \% \mathrm{Cl}$ intervals of the mixed models as well as other preregistered analyses can be found in the SI.

\section{Results}

\subsection{Day 1}

\subsubsection{US expectancy ratings}

The pairing of the CS with the US led to an increase in US expectancy ratings across acquisition trials [trial effect: $F(1,771)=315.84, p<.001$ ] (Fig. 2A).

\subsubsection{Eye blink startle responses}

Across the acquisition phase, startle responses were potentiated during the CS compared to baseline responding [intercept: $F(1,39)=24.699, p<.001$ ] (Fig. 2B).
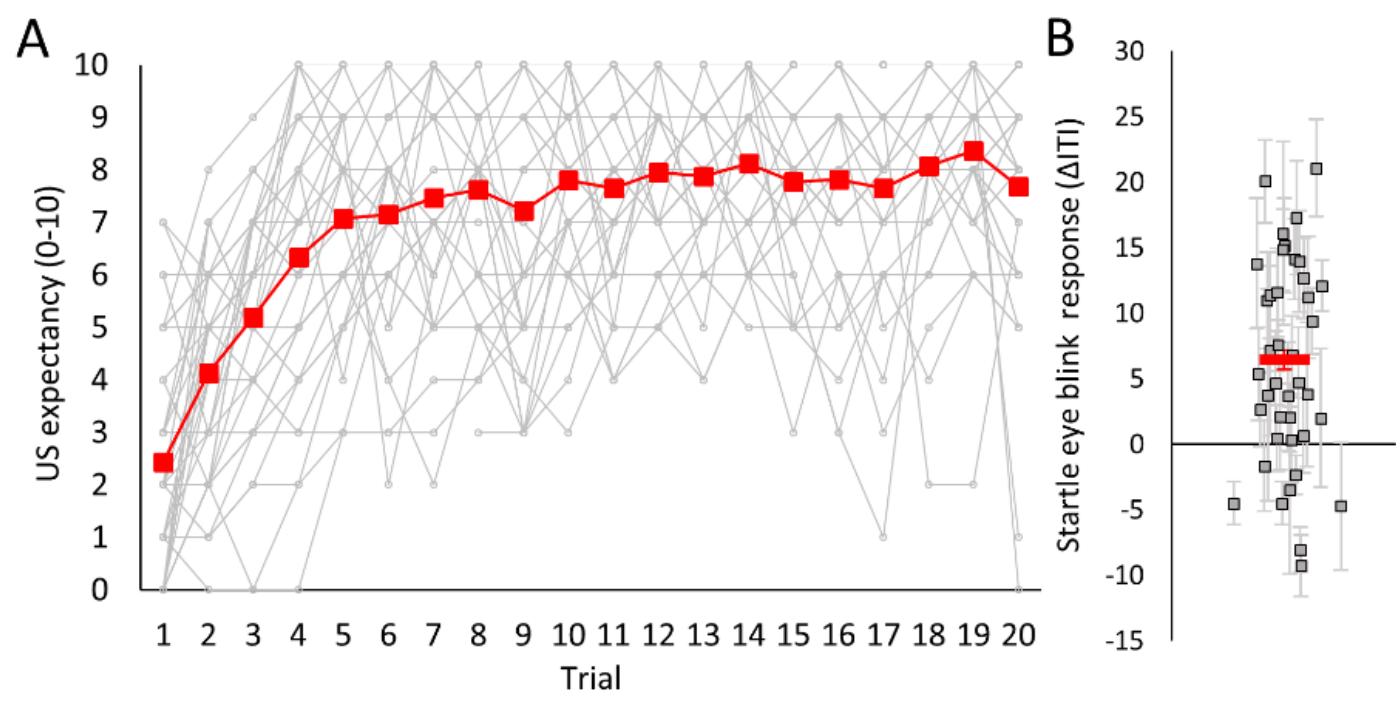

Fig. 2. (A) Averaged US expectancy ratings across acquisition trials (red line). The grey lines are US expectancy ratings per participant. (B) Averaged startle eye blink responses (red line) expressed as a difference score from baseline responding (i.e., average during noise alone trials (ITI) across both days).

\footnotetext{
${ }^{4}$ Deviating from the preregistration, a model with stimulus as a categorical predictor was adopted instead of a second-order polynomial with stimulus as continuous predictor, as this formalization was preferred based on

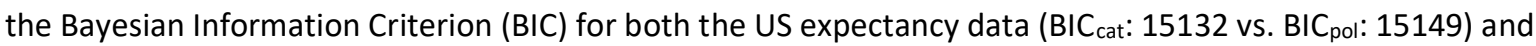
the startle data (BIC $\mathrm{Cat}_{\mathrm{c}} 9694$ vs. $\mathrm{BIC}_{\mathrm{pol}}$ : 9709), with lower BIC values indicating better fit. The parameter estimates from the original analyses can be found in the SI.
} 
The grey squares are the averaged startle eye blink response per participant. Error bars denote standard errors. US = unconditioned stimulus, ITI = interstimulus interval

\subsection{Day 2}

\subsubsection{Recall phase}

\subsubsection{Recalled CS size}

On the first trial of the recall phase, the averaged recalled CS size was $84.54 \mathrm{~mm}(S D=25.64)$ and increased to $96.91 \mathrm{~mm}(S D=15.17)$ on the last trial [trial effect: $F(1,358)=23.574, p<.001$ ]. Across trials, recall accuracy increased as it started to approach the CS size of $101.41 \mathrm{~mm}$ and the amount of variation decreased between participants (Fig. 3A).

\subsubsection{Recall uncertainty}

There was a significant main effect of trial [trial effect: $F(1,359)=48.11, p<.001$ ] with recall certainty increasing across trials (Fig. 3B).

\subsubsection{Retrospective US expectancy ratings}

The average retrospective US expectancy rating was 6.40 ( $S D=2.22$; Fig $3 \mathrm{E}$ ). Retrospective US expectancy did not significantly change across recall trials [trial effect: $F(1,359)=0.028, p=.867$ ]. 

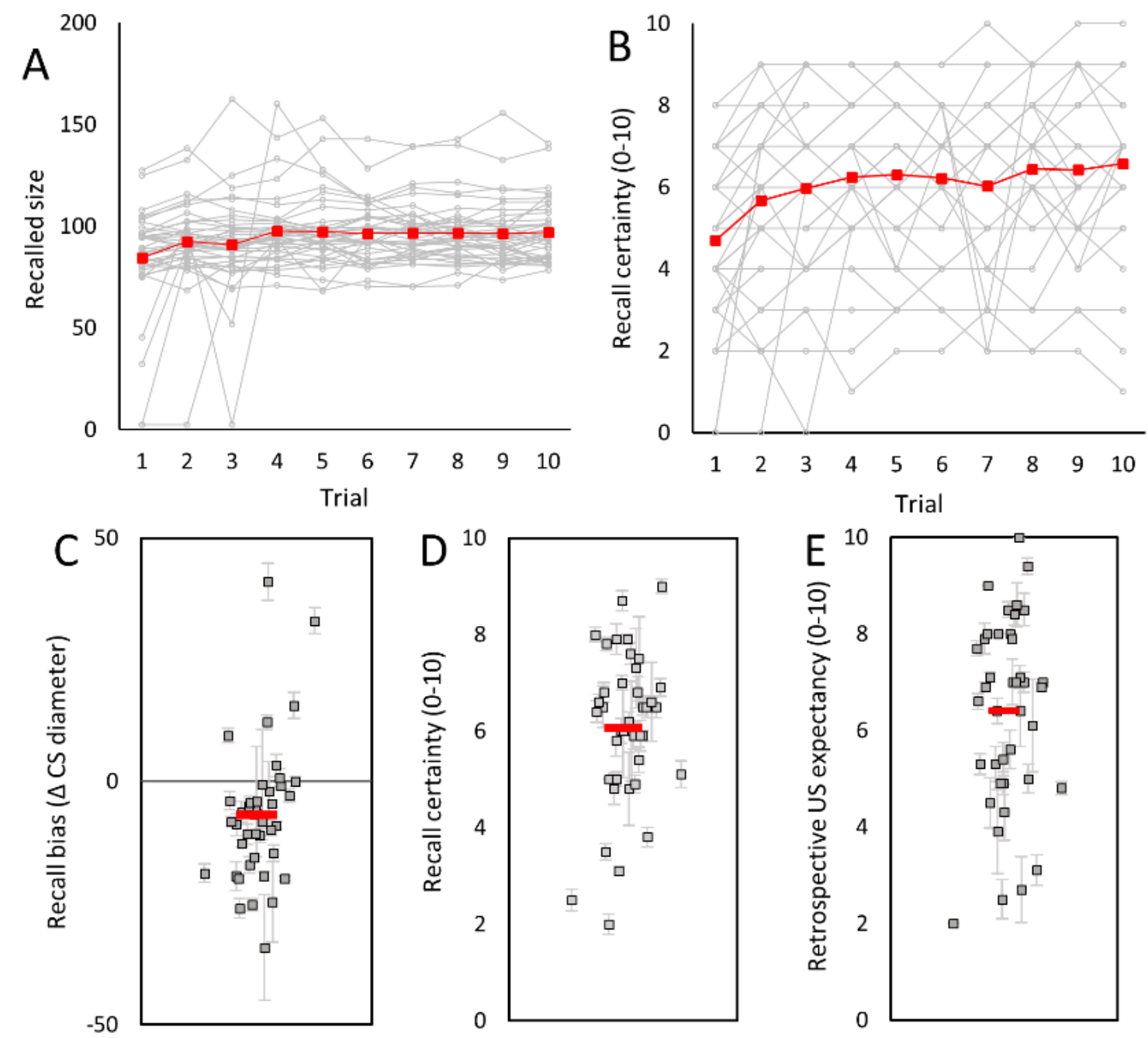

Fig. 3. (A-B) Recalled CS size and recall certainty ratings across trials averaged across participants (red) and per participants (grey). (C-E) The red line indicates the mean recall bias [calculated as the difference between mean recalled size $\left(\mu_{r}\right)$ and the CS diameter], self-reported recall certainty and retrospective US expectancy ratings during the recall phase on Day 2. The grey line in (C) denotes the physical size of the CS. The black squares are participants' averages. Error bars denote standard errors. $C S=$ conditioned stimulus, US = unconditioned stimulus .

\subsubsection{Generalization phase}

\subsubsection{US expectancy ratings}

Despite large inter-individual differences (Fig. 4A), significant differences in US expectancy ratings between test stimuli were found [stimulus effect $F(6,3362)=38.483, p<.001$ ]. In exploratory analyses, we tested whether the gradient was bell-shaped, and found a significant quadratic trend $[t(3363)=-$ $13.06, p<.001)]$. US expectancy ratings decreased across trials $[F(1,3362)=55.967, p<.001, b=-0.01$, 
$95 \% \mathrm{Cl}=(-0.01,-0.01)]$. Next, we investigated separately the influence of memory bias and uncertainty through their inclusion and interaction with stimulus.

Memory bias did not influence overall US expectancy ratings [recall bias effect: $F(1,38)=0.452 p=$ .505 ] but did affect ratings differently across the stimulus range [recall bias $\times$ stimulus effect: $F(6,3356)$ $=2.594, p=.016]$. In exploratory follow-up analyses, we investigated the asymmetry in the gradient for subjects that recalled the CS as smaller (negative recall bias, $n=33$ ) or as larger (positive recall bias, $n=7$ ). A positive recall bias led to an asymmetrical gradient as the right-hand side of the gradient was higher than the left-hand side of the gradient [left vs. right side: $t(2365)=2.382, p=.017$ ]. For the negative recall bias, no evidence for such an asymmetrical gradient was observed [left vs. right side: $t(2365)=1.023, p=.305]$ (Fig. 4B).

The effect of memory uncertainty was assessed using two measures: the averaged recall uncertainty ratings $\left(\mu_{u}\right)$, and the individual's variation in recalled CS size $\left(\sigma_{r}\right)$. Variation in recalled CS size did not affect overall US expectancy ratings or influence the gradients [recall variation effect: $F(1,38)=0.167$, $p=.685$; recall variation $\times$ stimulus effect: $F(6,3355)=1.00, p=.422$ ]. However, self-reported recall uncertainty did influence US expectancy ratings across the stimulus range [recall uncertainty $\times$ stimulus effect: $F(6,3356)=5.116, p<.001$; recall uncertainty effect: $F(1,38)=0.835, p=.367$ ]. In exploratory follow-up analyses, we split the sample into a high and low recall uncertainty group using a median split (median =6.4). As can be seen in Fig. 4 C, the gradient flattens for high recall uncertainty compared to the low recall uncertainty, supported by a significant interaction with quadratic trend [Quadratic contrast vs. recall uncertainty group: $\mathrm{t}(3357)=4.961, \mathrm{p}<.001]$.

Finally, effects of memory bias and uncertainty (and their interaction) were tested simultaneously. Memory uncertainty assessed by self-report only influenced the interaction between recall bias and stimulus [recall uncertainty $\times$ stimulus $\times$ recall bias effect: $F(6,3344)=2.306, p=.032$; recall uncertainty $\times$ recall bias effect: $F(1,36)<1, p=.983$ ]. For illustrative purposes, we plotted in Fig. 4D predicted US expectancy gradients for relative low (uncertainty rating of 7.62, based on $\mu_{u}+1 S D$ with $\mu_{u}=6.06$ and $S D=1.56$ ) and high levels of recall uncertainty (uncertainty of 4.50 , based on $\mu_{u}-1 S D$ ), and for a positive and negative recall bias set to 12.56 and -12.56 (12.56 is the average of the absolute values of the recall difference scores to reflect the overall strength of bias regardless of its direction). Higher levels of recall uncertainty seem to flatten the gradient more for a positive recall bias compared to a negative recall bias. In contrast, the more implicit measure of recall variation did not influence the effect of recall bias on US expectancy responses in any manner [recall variation $\times$ stimulus $\times$ recall bias effect: $F(6,3344)=1.424, p=.201$; recall variation $\times$ recall bias effect: $F(1,36)=0.267, p=.608$ ]. 

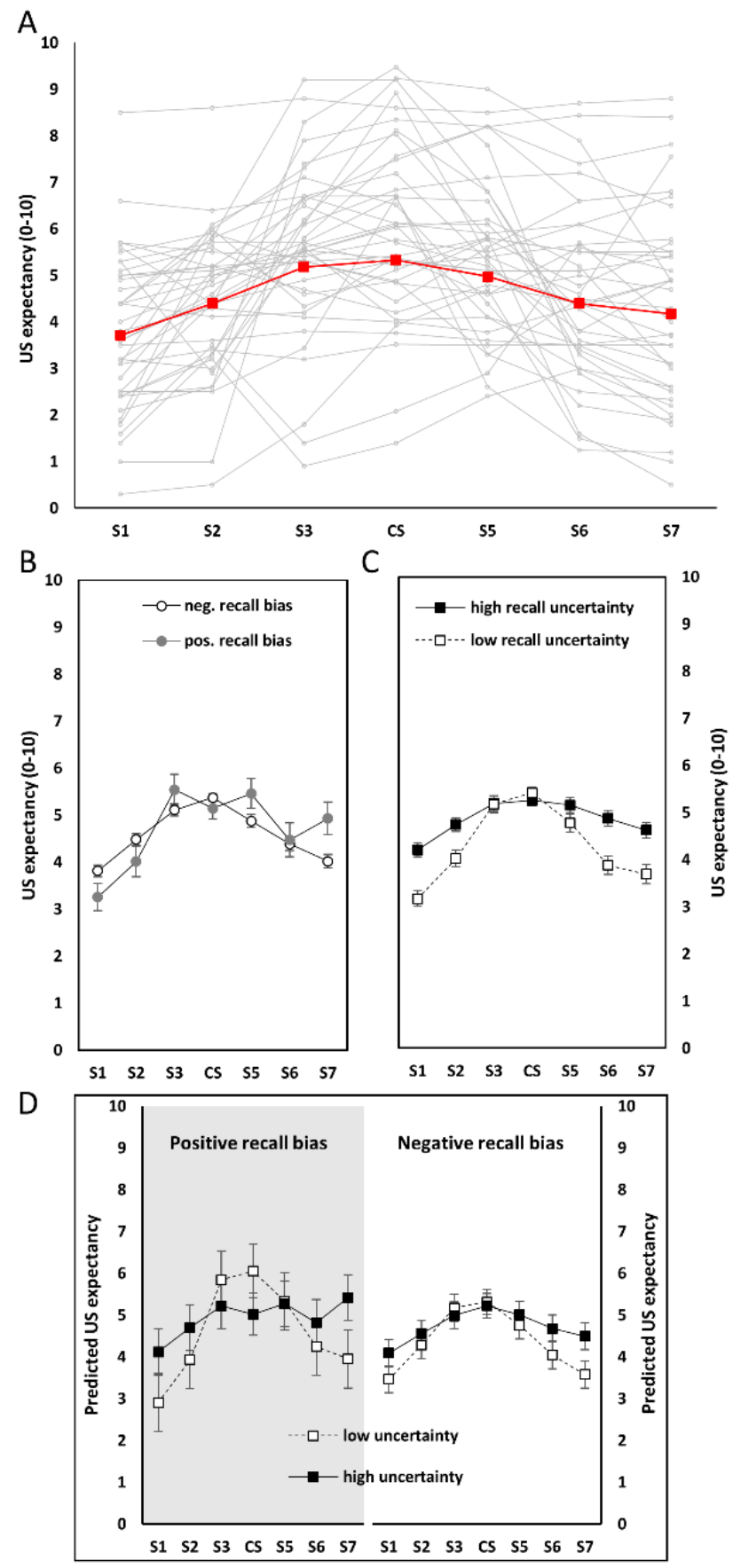

Fig. 4. (A) Averaged US expectancy ratings per stimulus across participants (red) and per participant (grey) from the generalization phase on Day 2. (B) Averaged US expectancies for a positive recall bias (participants that recalled the CS as larger than its actual size, $n=7$ ) and a negative recall bias (participants that recalled the CS as smaller than its actual size, $n=33$ ). (C) Averaged US expectancy ratings for the low ( $\leq 6.4)$ and high recall uncertainty groups (> 6.4) based on a median split. (D) Predicted US expectancies for the combination of a positive (12.56, based on the absolute mean recall bias) and negative recall bias (-12.56) and low and high levels of recall uncertainty (based on $\mu_{u} \pm 1 S D$ 
with $\mu_{u}=6.06$ and $\left.S D=1.56\right)$. Error bars denote standard errors. $S=$ generalization stimuli, $C S=$ conditioned stimulus, US = unconditioned stimulus, pos. = positive, neg. = negative .

\subsubsection{Startle eye blink responses}

Startle responses did not differ across the tested stimulus dimension [stimulus effect: $F(6,1274)=$ $0.387, p=.888$ ], although responses were potentiated compared to the baseline [intercept: $F(1,98)=$ 50.161, $p<.001$ ]. Responses habituated across trials [trial effect: $F(1,1274)=64.314, p<.001$ ] (Fig. $5 A)$.

Next, effects of memory bias and uncertainty (and their interaction) were assessed. Memory bias did not influence the strength of startle responding [recall bias effect: $F(1,37)=0.396, p=.533$ ] but did affect response strength differently across the stimulus range [recall bias $\times$ stimulus effect: $F(6,1268)$ $=2.581, p=.017]$. This effect was further explored similar to US expectancy analyses (Fig. 5B). However, these explorative analyses yielded no evidence for an asymmetry in either the positive or the negative bias group [pos. bias (left vs. right side): $t(242)=.624, p=.534$; neg. bias (left vs. right side): $t(1026)=$ $.337, p=.891]$. Additional explorative tests yielded no difference in responding between any of the stimuli in the negative recall group (all $p^{\prime} s=n s$ ). In the positive recall group, responding differed only between S1 and the CS $t(242)=3.014, p=.003$, all other tests failed to remain significant after a Bonferonni correction for multiple testing (all $p^{\prime} s=n s$ ).

Memory uncertainty assessed via self-report or variation in recalled size, did neither affect responding in general [recall uncertainty : $F(1,38)=0.422, p=.520$; recall variation: $F(1,37)=0.776, p=.384$ ] nor did it interact with stimulus [recall uncertainty $\times$ stimulus effect: $F(6,1269)=0.578, p=.748$; recall variation $\times$ stimulus effect: $F(6,1268)=0.910, p=.487]$.

Lastly, we tested for effects of memory bias and uncertainty and their interaction. Memory uncertainty assessed by self-report did not influence the effect of recall bias on response strength across the stimulus range [recall uncertainty $\times$ recall bias effect: $F(1,35)=3.217, p=.081$; recall uncertainty $\times$ recall bias $\times$ stimulus effect: $F(6,1256)=1.212, p=.972$ ], however, recall variation was found to affect the interaction between recall bias and stimulus [recall variation $\times$ recall bias $\times$ stimulus effect: $F(6,1256)=2.979, p=.007$; recall variation $\times$ recall bias effect: $F(1,36)=0.385, p=.539]$. As can be seen in Fig. 5C, patterns of startle responding became more similar between both types of recall bias when recall variation was high, whereas with a low recall variation pattern startle responses differed between positive and negative recall bias. 


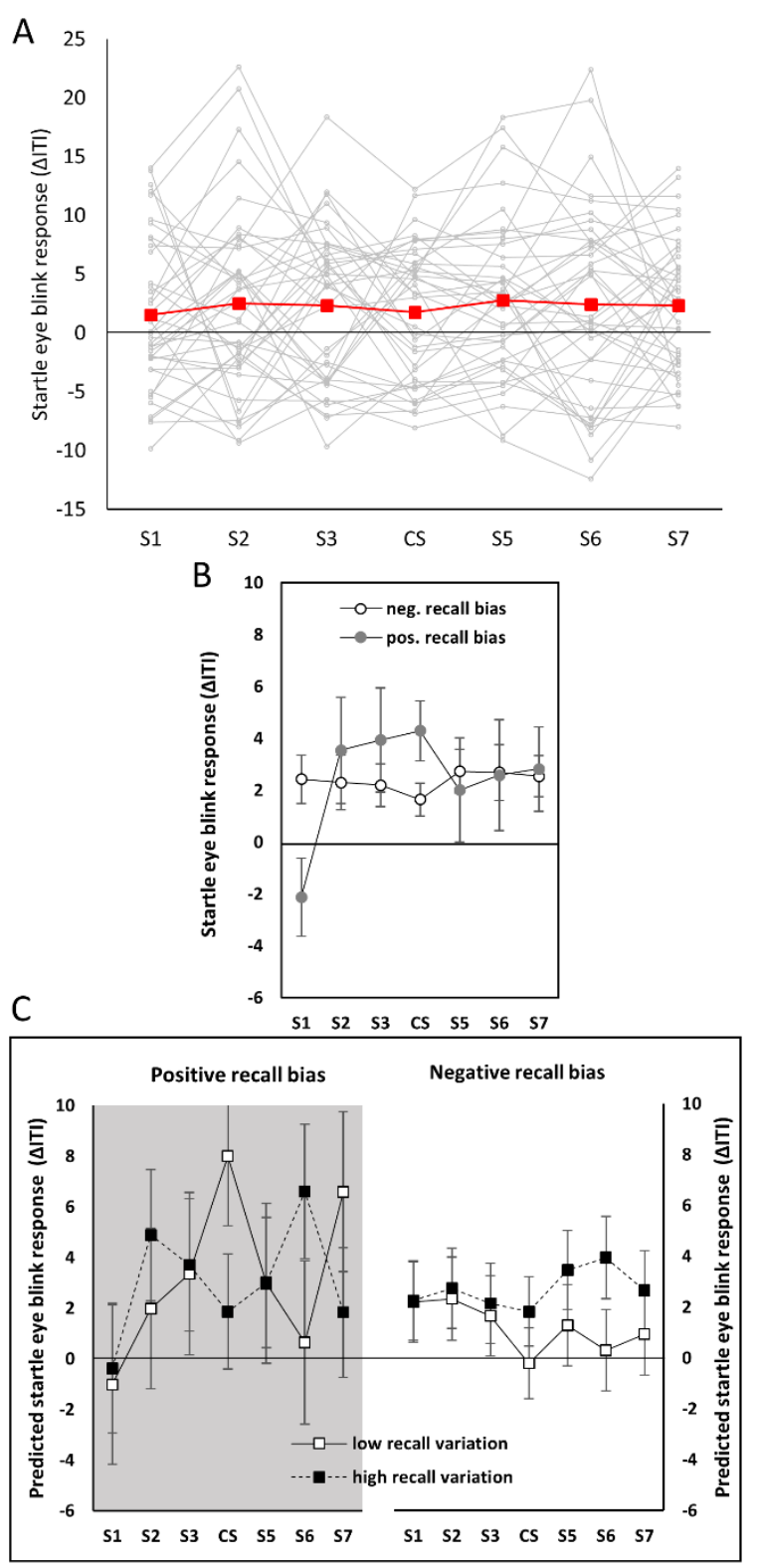

Fig. 5. (A) Startle eye blink responses per stimulus across participants (red) and per participant (grey) from the generalization phase on Day 2. Startle responses are expressed as difference scores from the mean startle responding during noise alone trials ( $\triangle I T I$, interstimulus interval). (B) Averaged startle eye blink responses for a positive recall bias (recalling the CS as larger) and a negative recall bias (recalling the CS as smaller). (C) Predicted startle eye blink responses for the combination between positive (12.56) and negative recall bias (-12.56) and low and high levels of recall variation (based on $\mu_{\sigma} \pm 1 S D$ with $\mu_{\sigma}=8.30$ and $\left.S D=9.14\right)$. Error bars denote standard errors. $S=$ generalization stimuli, $C S=$ conditioned stimulus, pos. = positive, neg. = negative, $I T I=$ interstimulusinterval 


\section{Discussions}

This study sought to investigate the role of perceptual memory bias and uncertainty on the generalization of a trained fear response across a range of physical similar stimuli. This study differs from the typical generalization study in separating training and test phases by 24 hours, and presenting a recall test of the training stimulus prior to assessing generalization. To the best of our knowledge, our experiment is the first to provide direct evidence that memory uncertainty results in broader generalization. Further, we found some evidence that memory bias influenced the pattern of generalized self-reported (US expectancy ratings) and psychophysiological responding (fear potentiated startle responses). Our findings suggest that memory is an important determinant of generalized behavior.

In our study, memory bias was assessed as the mean deviation during a recall adjustment task similar to previous studies (Allred, Crawford, Duffy, \& Smith, 2016; Huang \& Sekuler, 2010). As predicted, US expectancy ratings were elevated to larger test circles compared to their equidistant counterparts in participants with a positive recall bias (i.e., overestimated the CS size). This pattern of results is consistent with two previous studies that used a 2AFC categorization task (Struyf, Zaman, Hermans, \& Vervliet, 2017; in SI of Zaman, Struyf, Ceulemans, Beckers, \& Vervliet, 2019). However, unlike previous studies that found an effect of a negative recall bias, we found no asymmetry in expectancy ratings across the test dimension for participants with a negative recall bias (i.e., those who underestimated the CS size). One potential reason for the observed differential effect of memory bias is that the starting point (the anchor) in the adjustment task of the recall phase was always a small dot. LeBoef and Shafir (2006) demonstrated in a series of six studies that decreasing the size of an anchor, during an adjustment task, reliably led to size underestimations. This anchor effect, reducing overall estimations, may explain why such a large proportion of participants showed a negative recall bias (33/40) (Allred et al., 2016; LeBoeuf \& Shafir, 2006). Future studies should therefore use randomized or counterbalanced starting points to avoid potential anchor effects.

We also found an effect of memory bias on the startle potentiation gradients although the results were less straightforward. It remains unclear to which extent the extreme flat startle gradient might have acted as a ceiling effect. Upon testing on Day 2, all test stimuli elicited potentiated startle responses that did not differ from the initial trained fear response, indicating a high level of generalized fear. Hence, a potential asymmetry in response decline may be concealed by the absence of any response differentiation, indicative of maximal generalization. Although not designed to test for an effect of the 
delay between learning and testing, differences in gradients between this study and similar studies that tested generalization immediately after learning (Struyf, Zaman, Hermans, \& Vervliet, 2017; Zaman, Struyf, Ceulemans, Beckers, \& Vervliet, 2019) suggest that the $24 \mathrm{~h}$ delay period in the current study contributed to the flattening of the gradient. In our study, both US expectancy and startle gradients were much flatter (but not due to the absence of a response) compared to previous studies (Struyf, Zaman, Hermans, \& Vervliet, 2017; Zaman, Struyf, Ceulemans, Beckers, \& Vervliet, 2019), suggestive of more generalization. This observation fits with the proposal that generalization gradients flatten over time due to increased memory variability (Thomas \& Burr, 1969; Riccio et al., 1984).

Our second set of findings concern the effect of memory uncertainty. The key result was that memory uncertainty was related to flatter generalization gradients. This finding is in line with previous suggestions that the width of the memory distribution, reflective of its precision, has been proposed to increase the extent of generalization (Jasnow et al., 2012; Riccio et al., 1992, 1984). However, this theoretical account was predominantly based on indirect empirical evidence from animal research where longer delays between learning and testing flattenned generalization gradients (Perkins \& Weyant, 1958). Our experiment is the first to provide direct evidence that memory uncertainty results in more generalization behavior. We operationalized memory uncertainty in two ways: the amount of variation during the adjustment task (more implicit measure), and self-report (more explicit measure). Interestingly, we found differential effects of these indices. For US expectancy gradients, self-reported memory uncertainty broadend generalization, whereas for startle potentiation the effect was only found for recall variation (only in interaction with the memory bias effect). Interestingly, our two measures of memory uncertainty did not correlate (see $\mathrm{SI}$ ), suggesting they relate to different components of uncertainty. Conceptually, obtaining memory uncertainty using self-report ratings closely relates to the concept of metamemory cognitions (i.e., awareness about one's own memory capibilities) whereas response variation across recall trials does not (Nelson, 1990). Research should further investigate the extent to which these different aspects of memory uncertainty may explain previously reported divergences between explicit and implicit indices of fear learning (Holt et al., 2014; Sevenster, Beckers, \& Kindt, 2012, 2014).

Although we demonstrated inter-individual differences in the memory of a fear evoking stimulus and its influence on fear generalization, the underlying causes of these individual differences and their theoretical and clinical relevance remain to be elucidated. Especially in real life, determining the optimal extent of generalization is one of a subtle balance: too little generalization will result in suboptimal use of previous information, whereas excess generalization will result in cognitive and 
behavioral rigidity (Jäkel et al., 2008), which has been implicated in various pathologies including anxiety disorders (Kindt, 2014; Lissek, 2012). Insight into the determinants of this process is therefore of clinical importance as many different mechanisms including inaccurate perception, biased memory, or rigid cognitions may all yield the same seemingly pathological behavior, yet require distinct treatment forms.

Unlike previous studies, a key novel contribution of the current study was the assessment of memory and generalization using separate tasks. This enabled us to directly investigate the impact of memory on generalization. Furthermore, the use of a recall task instead of a recognition task enabled us to investigate perceptual memory in a detailed manner without affecting learning due to possible extinction learning. However, it seems that the repeated probing of participant's memory had some effect on judgements despite the fact that no feedback was provided during the recall task. Across recall trials subjects became more accurate and also more certain. Further, the continued reinforcement of the CS (to prevent extinction) during generalization testing, provided participants with new learning opportunities to correct any potential memory bias, thereby potentially undoing memory effects across test trials. Future studies are required to determine the optimal design for concurrent assessment of memory and generalization.

In sum, we have demonstrated that differences in the memory of an identical experience influence the extent to which people generalize from it. Models of generalization that assume a veridical representation between stimuli and their memory representation may account for group-level data, but fail to account for important differences between individuals or subgroups of participants (Lee, Hayes, \& Lovibond, 2018). Our data illustrate the need to account for these interindividal differences in perceptual memory when examining generalization of learned responses. 
Acknowledgments: JZ is a Postdoctoral Research Fellow of the Research Foundation Flanders (FWO, 12P8619N) and received funding from the Efic-Grunthal grant (EGG ID 358254826) and a Special Research Funds (FWO, 1500620N). The research was sponsored by the "Asthenes" long-term structural funding (METH/15/011) - Methusalem grant by the Flemish Government. 


\section{References}

Allred, S. R., Crawford, L. E., Duffy, S., \& Smith, J. (2016). Working memory and spatial judgments: Cognitive load increases the central tendency bias. Psychonomic Bulletin \& Review, 23(6), 1825-1831. https://doi.org/10.3758/s13423-016-1039-0

Blough, D. S. (1975). Steady sate data and a quantitative model of operant generalization and discrimination. Journal of Experimental Psychology: Animal Behavior Processes, 1(1), 3-21.

Blumenthal, T. D., Cuthbert, B. N., Filion, D. L., Hackley, S., Lipp, O. V, \& van Boxtel, A. (2005). Committee report: Guidelines for human startle eyeblink electromyographic studies. Psychophysiology, 42(1), 1-15. https://doi.org/10.1111/j.1469-8986.2005.00271.x

Bradley, M. M., \& Lang, P. J. (2000). Affective reactions to acoustic stimuli. Psychophysiology, 37(2), 204-215. https://doi.org/10.1111/1469-8986.3720204

Buysse, D. J., Reynolds, C. F., Monk, T. H., Berman, S. R., \& Kupfer, D. J. (1989). The Pittsburgh sleep quality index: A new instrument for psychiatric practice and research. Psychiatry Research, 28(2), 193-213. https://doi.org/10.1016/0165-1781(89)90047-4

Dunsmoor, J. E., Mitroff, S. R., \& LaBar, K. S. (2009). Generalization of conditioned fear along a dimension of increasing fear intensity. Learning \& Memory, 16(7), 460-469. https://doi.org/10.1101/Im.1431609

Dunsmoor, Joseph E., Mitroff, S. R., \& LaBar, K. S. (2009). Generalization of conditioned fear along a dimension of increasing fear intensity. Learning and Memory, 16(7), 460-469. https://doi.org/10.1101/Im.1431609

Ghirlanda, S., \& Enquist, M. (2003). A century of generalization. Animal Behaviour, 66(1), 15-36. https://doi.org/10.1006/anbe.2003.2174

Ghirlanda, S., \& Enquist, M. (2007). How training and testing histories affect generalization: A test of simple neural networks. Philosophical Transactions of the Royal Society B: Biological Sciences, 362(1479), 449-454. https://doi.org/10.1098/rstb.2006.1972

Holt, D. J., Boeke, E. A., Wolthusen, R. P. F., Nasr, S., Milad, M. R., \& Tootell, R. B. H. H. (2014). A parametric study of fear generalization to faces and Non-Face objects: Relationship to discrimination thresholds. Frontiers in Human Neuroscience, 8(SEP), 1-12. https://doi.org/10.3389/fnhum.2014.00624

Huang, J., \& Sekuler, R. (2010). Distortions in recall from visual memory: two classes of attractors at work. Journal of Vision, 10(2), 24.1-27. https://doi.org/10.1167/10.2.24

Jäkel, F., Schölkopf, B., \& Wichmann, F. A. (2007). A tutorial on kernel methods for categorization. Journal of Mathematical Psychology, 51(6), 343-358. https://doi.org/10.1016/j.jmp.2007.06.002

Jäkel, F., Schölkopf, B., \& Wichmann, F. A. (2008). Generalization and similarity in exemplar models of categorization: Insights from machine learning. Psychonomic Bulletin and Review, 15(2), 256-271. https://doi.org/10.3758/PBR.15.2.256

Jasnow, A. M., Cullen, P. K., \& Riccio, D. C. (2012). Remembering another aspect of forgetting. Frontiers in Psychology, 3(JUN), 1-8. https://doi.org/10.3389/fpsyg.2012.00175

Kindt, M. (2014). A behavioural neuroscience perspective on the aetiology and treatment of anxiety disorders. Behaviour Research and Therapy, 62, 24-36. https://doi.org/10.1016/j.brat.2014.08.012 
Lang, P. J., Davis, M., \& Ohman, A. (2000). Fear and anxiety: animal models and human cognitive psychophysiology. Journal of Affective Disorders, 61(3), 137-159. Retrieved from http://www.ncbi.nlm.nih.gov/pubmed/11163418

LeBoeuf, R. A., \& Shafir, E. (2006). The long and short of it: physical anchoring effects. Journal of Behavioral Decision Making, 19(4), 393-406. https://doi.org/10.1002/bdm.535

Lee, J. C., Hayes, B. K., \& Lovibond, P. F. (2018). Peak Shift and Rules in Human Generalization. Journal of Experimental Psychology: Learning Memory and Cognition, (January). https://doi.org/10.1037/xlm0000558

Lissek, S. (2012). Toward an account of clinical anxiety predicated on basic, neurally mapped mechanisms of Pavlovian fear-learning: the case for conditioned overgeneralization. Depression and Anxiety, 29(4), 257-263. https://doi.org/10.1002/da.21922

Lissek, S., Kaczkurkin, A. N., Rabin, S., Geraci, M., Pine, D. S., \& Grillon, C. (2014). Generalized anxiety disorder is associated with overgeneralization of classically conditioned-fear. Biological Psychiatry, 75(11), 909-915. https://doi.org/10.1016/j.biopsych.2013.07.025

McLaren, I. P. L., \& Mackintosh, N. J. (2002). Associative learning and elemental representation: II. Generalization and discrimination. Animal Learning \& Behavior, 30(3), 177-200. https://doi.org/10.3758/BF03192828

Mednick, S. A., \& Freedman, J. L. (1960). Stimulus generalization. Psychological Bulletin, 57(3), 169200. https://doi.org/10.1037/h0041650

Meijman, T. F., de Vries-Griever, A. H., De Vries, G., \& Kampman, R. (1988). The evaluation of the Groningen sleep quality scale. Groningen: Heymans Bulletin (HB 88-13-EX), 2006.

Nelson, T. O. (1990). Metamemory: A Theoretical Framework and New Findings. Psychology of Learning and Motivation - Advances in Research and Theory, 26(C), 125-173. https://doi.org/10.1016/S0079-7421(08)60053-5

Perkins, C. C., \& Weyant, R. G. (1958). The interval between training and test trials as a determiner of the slope of generalization gradients. Journal of Comparative and Physiological Psychology, 51(5), 596-600. https://doi.org/10.1037/h0042550

Riccio, D. C., Ackil, J., \& Burch-Vernon, A. (1992). Forgetting of stimulus attributes: methodological implications for assessing associative phenomena. Psychological Bulletin, 112(3), 433-445. https://doi.org/10.1037/0033-2909.112.3.433

Riccio, D. C., Richardson, R., \& Ebner, D. L. (1984). Memory retrieval deficits based upon altered contextual cues: A paradox. Psychological Bulletin, 96(1), 152-165. https://doi.org/10.1037/0033-2909.96.1.152

Robertson, E. M. (2018). Memory instability as a gateway to generalization. PLoS Biology, 16(3), 116. https://doi.org/10.1371/journal.pbio.2004633

Satterthwaite, F. E. (1946). An approximate distribution of estimates of variance components. Biometrics, 2(6), 110-114. https://doi.org/10.2307/3002019

Sevenster, D., Beckers, T., \& Kindt, M. (2012). Retrieval per se is not sufficient to trigger reconsolidation of human fear memory. Neurobiology of Learning and Memory, 97(3), 338345. https://doi.org/10.1016/j.nlm.2012.01.009

Sevenster, D., Beckers, T., \& Kindt, M. (2014). Fear conditioning of SCR but not the startle reflex requires conscious discrimination of threat and safety. Frontiers in Behavioral Neuroscience, 8. https://doi.org/10.3389/fnbeh.2014.00032 
Shepard, R. (1987). Toward a universal law of generalization for psychological science. Science, 237(4820), 1317-1323. https://doi.org/10.1126/science.3629243

Shepard, R. N. (1958). Stimulus and response generalization: Deduction of the generalization gradient from a trace model. Psychological Review, 65(4), 242-256.

https://doi.org/10.1037/h0043083

Spielberger, C. D., Gorsuch, R. C., Lushene, R. E., Vagg, P. R., \& Jacobs, G. A. (1983). Manual for the State-Trait Anxiety Inventory. Palo Alto: Consulting Psychologists Press.

Starita, F., Kroes, M. C. W., Davachi, L., Phelps, E. A., \& Dunsmoor, J. E. (2019). Threat learning promotes generalization of episodic memory. Journal of Experimental Psychology: General, 148(8), 1426-1434. https://doi.org/10.1037/xge0000551

Struyf, D., Zaman, J., Hermans, D., \& Vervliet, B. (2017). Gradients of fear: How perception influences fear generalization. Behaviour Research and Therapy, 93, 116-122.

https://doi.org/10.1016/j.brat.2017.04.001

Thomas, D. R., \& Burr, D. E. S. (1969). Stimulus generalization as a function of the delay between training and testing procedures: A reevaluation. Journal of the Experimental Analysis of Behavior, 12(I), 105-109. https://doi.org/10.1901/jeab.1969.12-105

Yarnitsky, D., Sprecher, E., Zaslansky, R., \& Hemli, J. a. (1995). Heat pain thresholds: normative data and repeatability. Pain, 60(3), 329-332. Retrieved from http://www.ncbi.nlm.nih.gov/pubmed/7596629

Zaman, J., Ceulemans, E., Hermans, D., \& Beckers, T. (2019). Direct and indirect effects of perception on generalization gradients. Behaviour Research and Therapy, 114(January), 44-50. https://doi.org/10.1016/j.brat.2019.01.006

Zaman, J., Struyf, D., Ceulemans, E., Beckers, T., \& Vervliet, B. (2019). Probing the role of perception in fear generalization. Scientific Reports, 9(1), 10026. https://doi.org/10.1038/s41598-01946176-x

Zaman, J., Vanpaemel, W., Aelbrecht, C., Tuerlinckx, F., \& Vlaeyen, J. W. S. (2017). Biased pain reports through vicarious information: A computational approach to investigate the role of uncertainty. Cognition, 169, 54-60. https://doi.org/10.1016/j.cognition.2017.07.009 
Differences in perceptual memory influence generalization patterns

Ann-Kathrin Zenses, Jessica Lee and Jonas Zaman

SUPPLEMENTAL MATERIAL 


\begin{tabular}{|c|c|c|c|c|c|c|}
\hline \multirow{2}{*}{$\begin{array}{l}\text { Day } 1 \text { - acquisition } \\
\text { Fixed effects }\end{array}$} & \multicolumn{2}{|c|}{ US expectancy } & \multicolumn{2}{|c|}{ Startle EMG } & \multicolumn{2}{|c|}{ Size } \\
\hline & Par. Est. (SE) & $95 \% \mathrm{Cl}$ & Par. Est. (SE) & $95 \% \mathrm{Cl}$ & Par. Est. (SE) & $95 \% \mathrm{Cl}$ \\
\hline Intercept & $4.97(0.228)^{* * *}$ & $4.515,5.428$ & $6.338(1.275)^{* * *}$ & $3.758,8.920$ & $68.394(4.821)$ & $58.655,78.132$ \\
\hline Trial & $0.197(0.011)^{* * *}$ & $0.175,0.219$ & - & - & $0.184(0.064)$ & $0.052,0.310$ \\
\hline \multicolumn{7}{|l|}{ Random effects } \\
\hline Variance RI & $1.427(.356)$ & - & 47.814 (14.427) & - & $905.92(206.368)$ & - \\
\hline Residual variance & $3.329(.169)$ & - & $103.074(9.570)$ & - & $104.153(5.44)$ & - \\
\hline
\end{tabular}

$\mathrm{RI}=$ Random Intercepts, $\mathrm{Cl}=$ Confidence Interval, $\wedge \leq .1,{ }^{*} \leq .05,{ }^{* *} \leq .01,{ }^{* * *} \leq .001$ 


\begin{tabular}{|c|c|c|c|c|c|c|}
\hline \multirow{2}{*}{$\begin{array}{l}\text { Day } 2 \text { - recall } \\
\text { Fixed effects }\end{array}$} & \multicolumn{2}{|c|}{ Size } & \multicolumn{2}{|c|}{ Uncertainty } & \multicolumn{2}{|c|}{ US expectancy } \\
\hline & Par. Est. (SE) & $95 \% \mathrm{Cl}$ & Par. Est. (SE) & $95 \% \mathrm{Cl}$ & Par. Est. (SE) & $95 \% \mathrm{Cl}$ \\
\hline Intercept & $89.103(2.570)^{* * *}$ & $83.961,94.244$ & $5.268(0.275)^{* * *}$ & $4.719,5.818$ & $6.408(0.329)$ & $5.748,7.068$ \\
\hline Trial & $0.997(0.205)^{* * *}$ & $0.593,1.400$ & $0.144(0.021)^{* * *}$ & $0.103,0.185$ & $0.184(0.064)$ & $-0.042,0.036$ \\
\hline \multicolumn{7}{|l|}{ Random effects } \\
\hline Variance RI & 199.109 (48.237) & - & $2.350(0.565)$ & - & $3.71(0.870)$ & - \\
\hline Residual variance & $138.143(10.325)$ & - & $1.421(0.106)$ & - & $1.30(0.097)$ & - \\
\hline
\end{tabular}

$\mathrm{RI}=$ Random Intercepts, $\mathrm{Cl}=$ Confidence Interval, ${ }^{\wedge} \leq .1,^{*} \leq .05,{ }^{* *} \leq .01,{ }^{* * *} \leq .001$ 


\begin{tabular}{|c|c|c|c|c|c|c|}
\hline \multirow{2}{*}{$\begin{array}{l}\text { Day } 2 \text { - US expectancy } \\
\text { Fixed effects }\end{array}$} & \multicolumn{2}{|c|}{ Model 1} & \multicolumn{2}{|c|}{ Model 2} & \multicolumn{2}{|c|}{ Model 3} \\
\hline & Par. Est. (SE) & $95 \% \mathrm{Cl}$ & Par. Est. (SE) & $95 \% \mathrm{Cl}$ & Par. Est. (SE) & $95 \% \mathrm{Cl}$ \\
\hline Intercept & $4.670(0.223)^{* * *}$ & $4.226,5.114$ & $4.670(0.224)^{* * *}$ & $4.224,5.117$ & $4.670(0.224)^{* * *}$ & $4.224,5.117$ \\
\hline Trial & $-0.011(0.002)^{* * *}$ & $\begin{array}{c}-0.014,- \\
0.008\end{array}$ & $-0.011(0.002)^{* * *}$ & $-0.015,-0.008$ & $-0.011(0.002)^{* * *}$ & $-0.015,-0.008$ \\
\hline Stimulus (S1) & $-0.469(0.153)^{* *}$ & $\begin{array}{c}-0.769,- \\
0.168\end{array}$ & $-0.469(0.153)^{* *}$ & $-0.769,-0.168$ & $-0.469(0.153)^{* *}$ & $-0.769,-0.168$ \\
\hline Stimulus (S2) & $0.210(0.153)$ & $-0.090,0.512$ & $0.211(0.153)$ & $-0.090,0.512$ & $0.211(0.153)$ & $-0.090,0.512$ \\
\hline Stimulus (S3) & $1.006(0.153)^{* * *}$ & $0.841,1.511$ & $1.006(0.153)^{* * *}$ & $0.706,1.307$ & $1.006(0.153)^{* * *}$ & $0.705,1.307$ \\
\hline Stimulus (S4 = CS) & $1.147(0.128)^{* * *}$ & $0.896,1.399$ & $1.147(0.128)^{* * *}$ & $0.896,1.399$ & $1.147(0.128)^{* * *}$ & $0.896,1.399$ \\
\hline Stimulus (S5) & $0.795(0.153)^{* * *}$ & $0.494,1.096$ & $0.796(0.153)^{* * *}$ & $0.495,1.096$ & $0.796(0.153)^{* * *}$ & $0.494,1.096$ \\
\hline Stimulus (S6) & $0.226(0.153)$ & $-0.075,0.526$ & $0.226(0.153)$ & $-0.074,0.526$ & $0.226(0.153)$ & $-0.075,0.526$ \\
\hline Stimulus (S7) & - & - & - & - & - & - \\
\hline Bias & & & $0.029(0.015)^{\wedge}$ & $-0.001,0.058$ & & \\
\hline S1 $\times$ Bias & & & $-0.036(0.011)^{* * *}$ & $-0.057,-0.015$ & & \\
\hline $\mathrm{S} 2 \times$ Bias & & & $-0.031(0.011)^{* *}$ & $-0.051,-0.010$ & & \\
\hline S3 $\times$ Bias & & & $-0.013(0.011)$ & $-0.034,0.007$ & & \\
\hline S4 $\times$ Bias & & & $-0.024(0.009)^{* *}$ & $-0.041,-0.006$ & & \\
\hline S5 $\times$ Bias & & & $-0.014(0.011)$ & $-0.034,0.007$ & & \\
\hline S6 $\times$ Bias & & & $-0.022(0.011)^{*}$ & $-0.043,-0.002$ & & \\
\hline S7 $\times$ Bias & & & - & - & & \\
\hline $\mathrm{SD}_{\mathrm{R}}$ & & & & & $0.019(0.024)$ & $-0.029,0.067$ \\
\hline $\mathrm{S} 1 \times \mathrm{SD}_{\mathrm{R}}$ & & & & & $-0.013(0.017)$ & $-0.046,0.021$ \\
\hline $\mathrm{S} 2 \times \mathrm{SD}_{\mathrm{R}}$ & & & & & $0.005(0.017)$ & $-0.028,0.039$ \\
\hline $\mathrm{S} 3 \times \mathrm{SD}_{\mathrm{R}}$ & & & & & $-0.023(0.017)$ & $-0.056,0.011$ \\
\hline $\mathrm{S} 4 \times \mathrm{SD}_{\mathrm{R}}$ & & & & & $-0.023(0.014)$ & $-0.051,0.005$ \\
\hline $\mathrm{S} 5 \times \mathrm{SD}_{\mathrm{R}}$ & & & & & $-0.009(0.017)$ & $-0.043,0.024$ \\
\hline $\mathrm{S} 6 \times \mathrm{SD}_{\mathrm{R}}$ & & & & & $-0.011(0.017)$ & $-0.044,0.022$ \\
\hline $\mathrm{S} 7 \times \mathrm{SD}_{\mathrm{R}}$ & & & & & - & - \\
\hline \multicolumn{7}{|l|}{ Random effects } \\
\hline Variance RI & $1.370(0.327)$ & - & $1.371(0.327)$ & - & $1.382(0.330)$ & - \\
\hline Residual variance & $4.751(0.116)$ & - & $4.710(0.115)$ & - & $4.724(0.115)$ & - \\
\hline
\end{tabular}




\begin{tabular}{|c|c|c|c|c|c|c|}
\hline \multirow{2}{*}{$\begin{array}{l}\text { Day } 2 \text { - US expectancy } \\
\text { Fixed effects }\end{array}$} & \multicolumn{2}{|c|}{ Model 4} & \multicolumn{2}{|c|}{ Model 5} & \multicolumn{2}{|c|}{ Model 6} \\
\hline & Par. Est. (SE) & $95 \% \mathrm{Cl}$ & Par. Est. (SE) & $95 \% \mathrm{Cl}$ & Par. Est. (SE) & $95 \% \mathrm{Cl}$ \\
\hline Intercept & $4.671(0.223)^{* * *}$ & $4.225,5.117$ & $4.672(0.227)^{* * *}$ & $4.220,5.125$ & $4.672(0.224)^{* * *}$ & $4.224,5.117$ \\
\hline Trial & $-0.011(0.002)^{* * *}$ & $\begin{array}{c}-0.014,- \\
0.008\end{array}$ & $-0.011(0.002)^{* * *}$ & $-0.014,-0.008$ & $-0.011(0.002)^{* * *}$ & $-0.015,-0.008$ \\
\hline Stimulus (S1) & $-0.470(0.153)^{* *}$ & $\begin{array}{c}-0.769,- \\
0.170\end{array}$ & $-0.470(0.153)^{* *}$ & $-0.769,-0.171$ & $-0.472(0.153)^{* *}$ & $-0.769,-0.168$ \\
\hline Stimulus (S2) & $0.210(0.153)$ & $-0.090,0.509$ & $0.210(0.153)$ & $-0.090,0.508$ & $0.199(0.153)$ & $-0.090,0.512$ \\
\hline Stimulus (S3) & $1.004(0.153)^{* * *}$ & $0.705,1.304$ & $1.003(0.153)^{* * *}$ & $0.706,1.302$ & $0.990(0.153)^{* * *}$ & $0.705,1.307$ \\
\hline Stimulus (S4 = CS) & $1.146(0.128)^{* * *}$ & $0.896,1.397$ & $1.145(0.128)^{* * *}$ & $0.895,1.395$ & $1.138(0.128)^{* * *}$ & $0.896,1.399$ \\
\hline Stimulus (S5) & $0.794(0.153)^{* * *}$ & $0.494,1.096$ & $0.793(0.153)^{* * *}$ & $0.495,1.096$ & $0.784(0.153)^{* * *}$ & $0.494,1.096$ \\
\hline Stimulus (S6) & $0.224(0.153)$ & $-0.075,0.523$ & $0.223(0.153)$ & $-0.074,0.526$ & $0.224(0.153)$ & $-0.075,0.526$ \\
\hline Stimulus (S7) & - & - & - & - & - & - \\
\hline Bias & & & $0.026(0.016)$ & $-0.006,0.058$ & $0.028(0.016)^{\wedge}$ & $-0.005,0.060$ \\
\hline S1 $\times$ Bias & & & $-0.037(0.011)^{* * *}$ & $-0.059,-0.015$ & $-0.035(0.011)^{* *}$ & $-0.057,-0.012$ \\
\hline $\mathrm{S} 2 \times$ Bias & & & $-0.031(0.011)^{* *}$ & $-0.052,-0.008$ & $-0.024(0.011)^{*}$ & $-0.047,-0.0002$ \\
\hline S3 $\times$ Bias & & & $-0.008(0.011)$ & $-0.030,0.014$ & $-0.005(0.011)$ & $-0.027,0.018$ \\
\hline S4 $\times$ Bias & & & $-0.016(0.009)^{\wedge}$ & $-0.033,0.003$ & $-0.019(0.009)^{*}$ & $-0.037,-0.001$ \\
\hline S5 $\times$ Bias & & & $-0.010(0.011)$ & $-0.032,0.012$ & $-0.008(0.011)$ & $-0.030,0.014$ \\
\hline S6 $\times$ Bias & & & $-0.019(0.011)^{\wedge}$ & $-0.041,0.002$ & $-0.022(0.011)^{\wedge}$ & $-0.044,0.001$ \\
\hline S7 $\times$ Bias & & & - & - & - & - \\
\hline$S D_{R}$ & & & & & $0.024(0.026)$ & $-0.028,0.077$ \\
\hline $\mathrm{S} 1 \times \mathrm{SD}_{\mathrm{R}}$ & & & & & $-0.019(0.019)$ & $-0.055,0.018$ \\
\hline $\mathrm{S} 2 \times \mathrm{SD}_{\mathrm{R}}$ & & & & & $-0.008(0.019)$ & $-0.044,0.029$ \\
\hline $\mathrm{S} 3 \times \mathrm{SD}_{\mathrm{R}}$ & & & & & $-0.040(0.019)^{*}$ & $-0.077,-0.004$ \\
\hline $\mathrm{S} 4 \times \mathrm{SD}_{\mathrm{R}}$ & & & & & $-0.034(0.016)^{*}$ & $-0.065,-0.004$ \\
\hline $\mathrm{S} 5 \times \mathrm{SD}_{\mathrm{R}}$ & & & & & $-0.022(0.019)$ & $-0.058,0.014$ \\
\hline $\mathrm{S} 6 \times \mathrm{SD}_{\mathrm{R}}$ & & & & & $-0.014(0.019)$ & $-0.051,0.022$ \\
\hline $\mathrm{S} 7 \times \mathrm{SD}_{\mathrm{R}}$ & & & & & - & - \\
\hline$\mu_{\mathrm{u}}$ & $-0.304(0.137)^{*}$ & $\begin{array}{c}-0.579,- \\
0.029\end{array}$ & $-0.332(0.148)^{*}$ & $-0.629,-0.036$ & & \\
\hline $\mathrm{S} 1 \times \mu_{\mathrm{u}}$ & $0.091(0.098)$ & $-0.102,0.283$ & $0.088(0.104)$ & $-0.114,0.292$ & & \\
\hline $\mathrm{S} 2 \times \mu_{\mathrm{u}}$ & $0.204(0.098)^{*}$ & $0.012,0.397$ & $0.207(0.104)^{*}$ & $0.003,0.410$ & & \\
\hline $\mathrm{S} 3 \times \mu_{\mathrm{u}}$ & $0.370(0.098)^{* * *}$ & $0.178,0.563$ & $0.421(0.104)^{* * *}$ & $0.217,0.625$ & & \\
\hline $\mathrm{S} 4 \times \mu_{\mathrm{u}}$ & $0.355(0.082)^{* * *}$ & $0.194,0.515$ & $0.431(0.082)^{* * *}$ & $0.261,0.601$ & & \\
\hline $\mathrm{S} 5 \times \mu_{\mathrm{u}}$ & $0.234(0.098)^{*}$ & $0.040,0.425$ & $0.276(0.104)^{* *}$ & $0.073,0.480$ & & \\
\hline $\mathrm{S} 6 \times \mu_{\mathrm{u}}$ & $0.100(0.098)$ & $-0.092,0.292$ & $0.131(0.104)$ & $-0.072,0.335$ & & \\
\hline $\mathrm{S} 7 \times \mu_{\mathrm{u}}$ & - & - & - & - & & \\
\hline Bias $\times \mu_{u}$ & & & $-0.007(0.012)$ & $-0.031,0.018$ & & \\
\hline $\mathrm{S} 1 \times \operatorname{Bias} \times \mu_{\mathrm{u}}$ & & & $-0.008(0.009)$ & $-0.018,0.016$ & & \\
\hline $\mathrm{S} 2 \times$ Bias $\times \mu_{\mathrm{u}}$ & & & $0.000(0.009)$ & $-0.016,0.017$ & & \\
\hline $\mathrm{S} 3 \times \operatorname{Bias} \times \mu_{\mathrm{u}}$ & & & $0.123(0.009)$ & $-0.004,0.029$ & & \\
\hline $\mathrm{S} 4 \times \operatorname{Bias} \times \mu_{\mathrm{u}}$ & & & $0.0187(0.007)^{* *}$ & $0.005,0.033$ & & \\
\hline S5 $\times$ Bias $\times \mu_{u}$ & & & $0.011(0.009)$ & $-0.006,0.027$ & & \\
\hline S6 $\times$ Bias $\times \mu_{u}$ & & & $0.008(0.009)$ & $-0.009,0.024$ & & \\
\hline$S 7 \times$ Bias $\times \mu_{u}$ & & & - & - & & \\
\hline Bias $\times \mathrm{SD}_{\mathrm{R}}$ & & & & & $0.001(0.002)$ & $-0.003,0.004$ \\
\hline $\mathrm{S} 1 \times$ Bias $\times \mathrm{SD}_{\mathrm{R}}$ & & & & & $-0.001(0.001)$ & $-0.003,0.002$ \\
\hline $\mathrm{S} 2 \times \operatorname{Bias} \times \mathrm{SD}_{\mathrm{R}}$ & & & & & $-0.002(0.001)$ & $-0.005,0.001$ \\
\hline $\mathrm{S} 3 \times$ Bias $\times \mathrm{SD}_{\mathrm{R}}$ & & & & & $-0.003(0.001)^{*}$ & $-0.006,-0.001$ \\
\hline $\mathrm{S} 4 \times$ Bias $\times \mathrm{SD}_{\mathrm{R}}$ & & & & & $-0.002(0.001)$ & $-0.004,0.001$ \\
\hline $\mathrm{S} 5 \times$ Bias $\times \mathrm{SD}_{\mathrm{R}}$ & & & & & $-0.002(0.001)$ & $-0.005,0.001$ \\
\hline $\mathrm{S} 6 \times$ Bias $\times \mathrm{SD}_{\mathrm{R}}$ & & & & & $-0.001(0.001)$ & $-0.003,0.002+$ \\
\hline
\end{tabular}


$\mathrm{S} 7 \times$ Bias $\times \mathrm{SD}_{\mathrm{R}}$

\begin{tabular}{|c|c|c|c|c|c|c|}
\hline \multicolumn{7}{|l|}{ Random effects } \\
\hline Variance RI & $1.368(0.327)$ & - & $1.430(0.350)$ & - & $1.433(0.3510)$ & - \\
\hline Residual variance & $4.690(0.114)$ & - & $4.67(0.114)$ & - & $4.707(0.115)$ & - \\
\hline
\end{tabular}

$\mathrm{RI}=$ Random Intercepts, $\mathrm{Cl}=$ Confidence Interval, $\mathrm{SD}_{\mathrm{R}}=$ standard deviation during recall, $\mathrm{S} 7$ serves as reference, $\mu_{\mathrm{u}}=$ mean uncertainty rating $\wedge<.1, *<.05, * *$ $\leq .01, * * * .001$ 


\begin{tabular}{|c|c|c|c|c|c|c|}
\hline \multirow{2}{*}{$\begin{array}{l}\text { Day } 2 \text { - Startle } \\
\text { Fixed effects }\end{array}$} & \multicolumn{2}{|c|}{ Model 1} & \multicolumn{2}{|c|}{ Model 2} & \multicolumn{2}{|c|}{ Model 3} \\
\hline & Par. Est. (SE) & $95 \% \mathrm{Cl}$ & Par. Est. (SE) & $95 \% \mathrm{Cl}$ & Par. Est. (SE) & $95 \% \mathrm{Cl}$ \\
\hline Intercept & $7.481(1.228)^{* * *}$ & $5.060,9.903$ & $7.511(1.228)^{* * *}$ & $5.088,9.933$ & $7.523(1.230)^{* * *}$ & $5.097,9.950$ \\
\hline Trial & $-0.142(0.018)^{* * *}$ & $\begin{array}{c}-0.177,- \\
0.107\end{array}$ & $-0.142(0.018)^{* * *}$ & $-0.177,-0.107$ & $-0.143(0.018)^{* * *}$ & $-0.177,-0.108$ \\
\hline Stimulus (S1) & $-1.034(1.021)$ & $-3.037,0.969$ & $-1.018(1.017)$ & $-3.014,0.977$ & $-1.034(1.021)$ & $-3.038,0.969$ \\
\hline Stimulus (S2) & $0.084(1.031)$ & $-1.938,2.107$ & $0.083(1.028)$ & $-1.934,2.100$ & $0.087(1.031)$ & $-1.936,2.110$ \\
\hline Stimulus (S3) & $-0.040(1.023)$ & $-2.047,1.967$ & $-0.015(1.020)$ & $-2.016,1.986$ & $-0.051(1.023)$ & $-2.059,1.957$ \\
\hline Stimulus (S4 = CS) & $-0.580(0.884)$ & $-2.315,1.155$ & $-0.574(0.881)$ & $-2.303,1.155$ & $-0.586(0.885)$ & $-2.321,1.150$ \\
\hline Stimulus (S5) & $0.001(1.019)$ & $-1.998,2.000$ & $-0.004(1.016)$ & $-1.996,1.989$ & 0.009 (1.019) & $-2.010,1.991$ \\
\hline Stimulus (S6) & $0.043(1.027)$ & $-1.972,2.058$ & $0.053(1.024)$ & $-1.954,2.061$ & $0.125(1.028)$ & $-1.893,2.142$ \\
\hline Stimulus (S7) & - & - & - & - & - & - \\
\hline Bias & & & $0.060(0.071)$ & $-0.081,0.200$ & & \\
\hline S1 $\times$ Bias & & & $-0.072(0.067)^{*}$ & $-0.305,-0.040$ & & \\
\hline $\mathrm{S} 2 \times$ Bias & & & $-0.008(0.068)$ & $-0.142,0.125$ & & \\
\hline S3 $\times$ Bias & & & $0.004(0.067)$ & $-0.128,0.136$ & & \\
\hline S4 $\times$ Bias & & & $0.046(0.058)$ & $-0.068,0.160$ & & \\
\hline S5 $\times$ Bias & & & $-0.052(0.67)$ & $-0.183,0.080$ & & \\
\hline S6 $\times$ Bias & & & $0.008(0.068)$ & $-0.125,0.141$ & & \\
\hline S7 $\times$ Bias & & & - & - & & \\
\hline $\mathrm{SD}_{\mathrm{R}}$ & & & & & $0.062(0.115)$ & $-0.165,0.289$ \\
\hline $\mathrm{S} 1 \times \mathrm{SD}_{\mathrm{R}}$ & & & & & $-0.062(0.111)$ & $-0.278,0.155$ \\
\hline $\mathrm{S} 2 \times \mathrm{SD}_{\mathrm{R}}$ & & & & & $-0.033(0.111)$ & $-0.250,0.184$ \\
\hline $\mathrm{S} 3 \times \mathrm{SD}_{\mathrm{R}}$ & & & & & $-0.043(0.111)$ & $-0.260,0.174$ \\
\hline $\mathrm{S} 4 \times \mathrm{SD}_{\mathrm{R}}$ & & & & & $0.035(0.095)$ & $-0.152,0.222$ \\
\hline $\mathrm{S} 5 \times \mathrm{SD}_{\mathrm{R}}$ & & & & & $0.052(0.111)$ & $-0.163,0.266$ \\
\hline $\mathrm{S} 6 \times \mathrm{SD}_{\mathrm{R}}$ & & & & & $0.165(0.111)$ & $-0.059,0.388$ \\
\hline $\mathrm{S} 7 \times \mathrm{SD}_{\mathrm{R}}$ & & & & & - & - \\
\hline \multicolumn{7}{|l|}{ Random effects } \\
\hline Variance RI & 22.619 (5.778) & - & 22.837 (5.902) & - & $22.782(5.893)$ & - \\
\hline Residual variance & 84.901 (3.365) & - & 84.277 (3.348) & - & 84.934 (3.375) & - \\
\hline
\end{tabular}




\begin{tabular}{|c|c|c|c|c|c|c|}
\hline \multirow{2}{*}{$\begin{array}{l}\text { Day } 2 \text { - Startle } \\
\text { Fixed effects }\end{array}$} & \multicolumn{2}{|c|}{ Model 4} & \multicolumn{2}{|c|}{ Model 5} & \multicolumn{2}{|c|}{ Model 6} \\
\hline & Par. Est. (SE) & $95 \% \mathrm{Cl}$ & Par. Est. (SE) & $95 \% \mathrm{Cl}$ & Par. Est. (SE) & $95 \% \mathrm{Cl}$ \\
\hline Intercept & $7.490(1.232)^{* * *}$ & $5.059,9.921$ & $7.541(1.220)^{* * *}$ & $5.136,9.948$ & $7.488(1.229)^{* * *}$ & $5.059,9.921$ \\
\hline Trial & $-0.142(0.018)^{* * *}$ & $-0.177,-0.107$ & $-0.142(0.018)^{* * *}$ & $-0.177,-0.107$ & $-0.142(0.018)^{* * *}$ & $-0.177,-0.107$ \\
\hline Stimulus (S1) & $-1.046(1.022)$ & $-3.052,0.959$ & $-1.045(1.018)$ & $-3.043,0.953$ & $-0.975(1.013)$ & $-2.963,1.012$ \\
\hline Stimulus (S2) & $0.063(1.032)$ & $-1.963,2.089$ & $0.108(1.030)$ & $-1.913,2.128$ & $0.214(1.026)$ & $-1.798,2.227$ \\
\hline Stimulus (S3) & $-0.083(1.024)$ & $-2.094,1.928$ & $-0.060(1.021)$ & $-2.064,1.943$ & $0.018(1.016)$ & $-1.975,2.012$ \\
\hline Stimulus (S4 = CS) & $-0.590(0.886)$ & $-2.329,1.148$ & $-0.589(0.883)$ & $-2.320,1.142$ & $-0.682(0.878)$ & $-2.406,1.040$ \\
\hline Stimulus (S5) & $0.001(1.020)$ & $-2.002,2.003$ & $-0.003(1.017)$ & $-1.998,1.992$ & $-0.004(1.012)$ & $-1.989,1.982$ \\
\hline Stimulus (S6) & $0.073(1.029)$ & $-1.946,2.091$ & $0.076(1.026)$ & $-1.936,2.089$ & $0.145(1.012)$ & $-1.856,2.146$ \\
\hline Stimulus (S7) & - & - & - &.- & - & - \\
\hline Bias & & & $0.080(0.074)$ & $-0.068,0.277$ & $0.100(0.075)$ & $-0.049,0.250$ \\
\hline $\mathrm{S} 1 \times$ Bias & & & $-0.130(0.073)$ & $-0.273,0.013$ & $-0.217(0.071)^{* *}$ & $-0.357,-0.077$ \\
\hline $\mathrm{S} 2 \times$ Bias & & & $0.034(0.072)$ & $-0.108,0.176$ & $-0.064(0.072)$ & $-0.206,0.078$ \\
\hline S3 $\times$ Bias & & & $0.008(0.072)$ & $-0.133,0.150$ & $-0.038(0.071)$ & $-0.178,0.102$ \\
\hline $\mathrm{S} 4 \times$ Bias & & & $0.048(0.062)$ & $-0.074,0.169$ & $0.065(0.061)$ & $-0.056,0.185$ \\
\hline $\mathrm{S} 5 \times$ Bias & & & $-0.057(0.072)$ & $-0.198,0.084$ & $-0.070(0.071)$ & $-0.211,0.069$ \\
\hline $\mathrm{S} 6 \times$ Bias & & & $0.014(0.074)$ & $-0.131,0.159$ & $-0.035(0.071)$ & $-0.175,0.105$ \\
\hline S7 $\times$ Bias & & & - & - & - & - \\
\hline $\mathrm{SD}_{\mathrm{R}}$ & & & & & $-0.008(0.125)$ & $-0.257,0.240$ \\
\hline $\mathrm{S} 1 \times \mathrm{SD}_{\mathrm{R}}$ & & & & & $0.009(0.118)$ & $-0.223,0.240$ \\
\hline $\mathrm{S} 2 \times \mathrm{SD}_{\mathrm{R}}$ & & & & & $0.060,(0.118)$ & $-0.172,0.292$ \\
\hline $\mathrm{S} 3 \times \mathrm{SD}_{\mathrm{R}}$ & & & & & $0.040(0.121)$ & $-0.197,0.277$ \\
\hline $\mathrm{S} 4 \times \mathrm{SD}_{\mathrm{R}}$ & & & & & $-0.004(0.102)$ & $-0.205,0.197$ \\
\hline $\mathrm{S} 5 \times \mathrm{SD}_{\mathrm{R}}$ & & & & & $0.085(0.119)$ & $-0.147,0.318$ \\
\hline $\mathrm{S} 6 \times \mathrm{SD}_{\mathrm{R}}$ & & & & & $0.244(0.121)^{*}$ & $0.006,0.482$ \\
\hline $\mathrm{S} 7 \times \mathrm{SD}_{\mathrm{R}}$ & & & & & - & - \\
\hline$\mu_{\mathrm{u}}$ & $0.082(0.673)$ & $-1.252,1.416$ & $0.340(0.713)$ & $-1.075,1.755$ & & \\
\hline $\mathrm{S} 1 \times \mu_{u}$ & $0.004(0.662)$ & $-1.294,1.302$ & $0.353(0.699)$ & $-1.019,1.753$ & & \\
\hline $\mathrm{S} 2 \times \mu_{u}$ & $0.376(0.663)$ & $-0.925,1.678$ & $0.676(0.689)$ & $-0.676,2.028$ & & \\
\hline $\mathrm{S} 3 \times \mu_{u}$ & $-0.116(0.641)$ & $-1.373,1.141$ & $-0.092(0.680)$ & $-1.427,1.242$ & & \\
\hline $\mathrm{S} 4 \times \mu_{u}$ & $0.115(0.571)$ & $-1.005,1.235$ & $0.147(0.560)$ & $-1.030,1.323$ & & \\
\hline $\mathrm{S} 5 \times \mu_{u}$ & $0.670(0.654)$ & $-0.617,1.953$ & $0.640(0.691)$ & $-0.716,1.996$ & & \\
\hline $\mathrm{S} 6 \times \mu_{u}$ & $0.720(0.640)$ & $-0.531,1.972$ & $0.785(0.677)$ & $-0.542,2.113$ & & \\
\hline$S 7 \times \mu_{u}$ & - & - & - & . & & \\
\hline Bias $\times \mu_{u}$ & & & $0.050(0.056)$ & $-0.062,0.161$ & & \\
\hline $\mathrm{S} 1 \times$ Bias $\times \mu_{u}$ & & & $0.082(0.055)$ & $-0.027,0.190$ & & \\
\hline $\mathrm{S} 2 \times$ Bias $\times \mu_{u}$ & & & $0.099(0.056)$ & $-0.010,0.207$ & & \\
\hline $\mathrm{S} 3 \times$ Bias $\times \mu_{u}$ & & & $0.008(0.053)$ & $-0.098,0.113$ & & \\
\hline$S 4 \times$ Bias $\times \mu_{u}$ & & & $0.003(0.047)$ & $-0.088,0.095$ & & \\
\hline $\mathrm{S} 5 \times$ Bias $\times \mu_{u}$ & & & $-0.008(0.054)$ & $-0.115,0.098$ & & \\
\hline $\mathrm{S} 6 \times$ Bias $\times \mu_{u}$ & & & $0.019(0.054)$ & $-0.088,0.125$ & & \\
\hline$S 7 \times$ Bias $\times \mu_{u}$ & & & - & - & & \\
\hline Bias $\times \mathrm{SD}_{\mathrm{R}}$ & & & & & $-0.014(0.009)$ & $-0.032,0.004$ \\
\hline $\mathrm{S} 1 \times$ Bias $\times \mathrm{SD}_{\mathrm{R}}$ & & & & & $0.015(0.009)^{\wedge}$ & $-0.002,0.032$ \\
\hline $\mathrm{S} 2 \times$ Bias $\times \mathrm{SD}_{\mathrm{R}}$ & & & & & $0.018(0.009)^{*}$ & $0.001,0.036$ \\
\hline $\mathrm{S} 3 \times$ Bias $\times \mathrm{SD}_{\mathrm{R}}$ & & & & & $0.014(0.009)^{\wedge}$ & $-0.003,0.031$ \\
\hline $\mathrm{S} 4 \times$ Bias $\times \mathrm{SD}_{\mathrm{R}}$ & & & & & $-0.004(0.007)$ & $-0.019,0.010$ \\
\hline $\mathrm{S} 5 \times$ Bias $\times \mathrm{SD}_{\mathrm{R}}$ & & & & & $0.008(0.009)$ & $-0.009,0.025$ \\
\hline $\mathrm{S} 6 \times$ Bias $\times \mathrm{SD}_{\mathrm{R}}$ & & & & & $0.017(0.009)^{\wedge}$ & $-0.001,0.035$ \\
\hline $\mathrm{S} 7 \times$ Bias $\times \mathrm{SD}_{\mathrm{R}}$ & & & & & - & - \\
\hline
\end{tabular}

\begin{tabular}{|c|c|c|c|c|c|c|}
\hline Random effects & & & & & & \\
\hline Variance RI & 22.958 (5.937) & - & $84.366(3.368)$ & - & $83.500(3.333)$ & - \\
\hline Residual variance & 85.076 (3.380) & - & $21.955(5.853)$ & - & $23.169(6.140)$ & - \\
\hline
\end{tabular}

$\mathrm{RI}=$ Random Intercepts , $\mathrm{Cl}=$ Confidence Interval, $\mathrm{SD}_{\mathrm{R}}=$ standard deviation during recall, $\mathrm{S} 7$ serves as reference, $\mu_{\mathrm{u}}=$ mean uncertainty rating ${ }^{\wedge} \leq .1,{ }^{*} \leq .05, * *$ $\leq .01, * * * .001$ 


\section{Size estimation}

The diameter of the CS was estimated to be $70.50 \mathrm{~mm}(S D=31.52)$ on average across trials (Fig. S1A), and estimates increased across trials [trial effect: $F(1,733.02)=8.32, p=.004,6=.18, S E=.06]$.
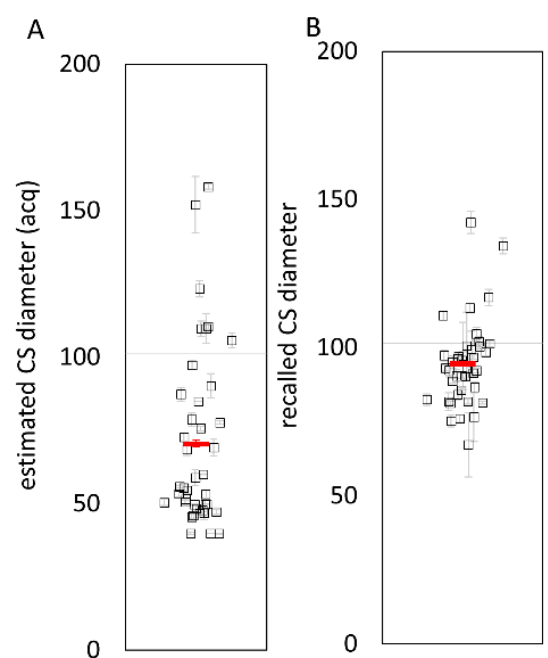
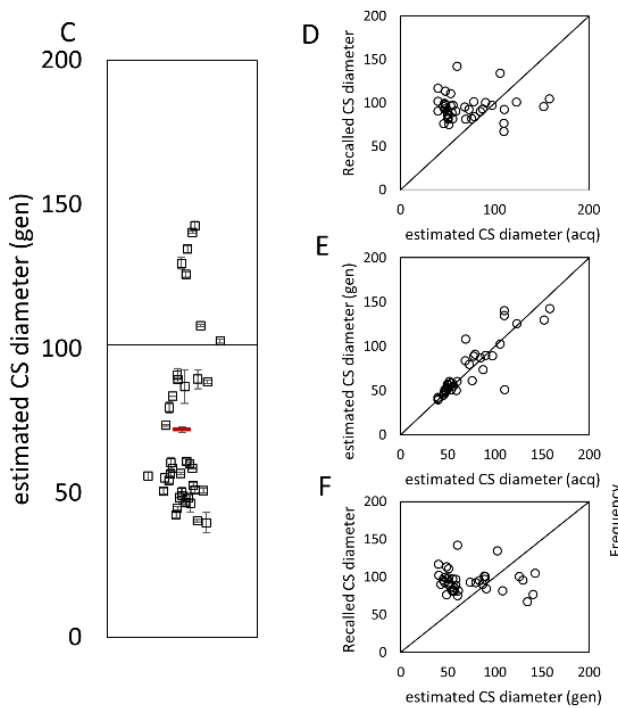
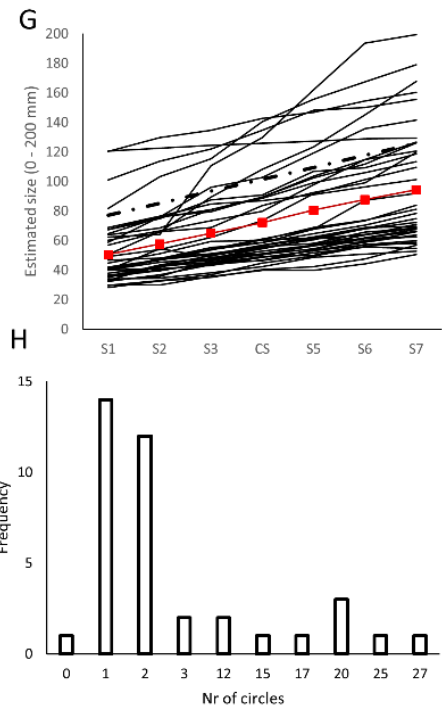

Fig. S1. (A-C) Mean CS size estimate during acquisition, recall and generalization (in $\mathrm{mm}$ ). Red line is the group average, the grey line indicated the size of the CS. (D-F) Explorative scatterplots between estimated and recalled CS size. (G) Averaged size estimates during the generalization phase across participants (red) and per participants (black). The dotted line indicates the true physical size of the stimuli. $(H)$ Frequency chart of the retrospective number estimate of the number of different CSs. Error bars denote standard errors. $S=$ generalization stimuli, $C S=$ conditioned stimulus. 
Day 2

Recall phase

CS count

The bulk of participants reported to be exposed on Day 1 to either one or two stimuli whereas a small subgroup thought many more stimuli were presented on day 1 (see Fig. S1H).

\section{Correlations}

In exploratory analyses, we calculated the correlations between the mean CS estimated size (separately for acquisition and generalization) and the mean recalled CS (Fig. S1D-F). CS size estimates on both days strongly correlated $(r=.928, p<.001)$ and both did not correlate with recalled CS size $\left(r_{a c q}=.040, p=.804 ; r_{\text {gen }}=\right.$ $-.102, p=.535)$. Furthermore, there was no correlation between US expectancy ratings on the last trial of acquisition and mean retrospective US expectancy ratings ( $r=.155, p=.340$ ). Finally, we calculated correlations between the amount of variance in estimated CS size across acquisition, recall uncertainty and recall variation. Variation in estimated CS size did not correlate with recall uncertainty $(r=.029, p=.859)$ or recall variation $(r=.079, p=.627)$, neither was there a relationship between both indices of memory uncertainty $(r=.016, p=.920)$. All reported $p$-values are uncorrected for multiple testing.

\section{Generalization phase}

\section{Size estimates}

Size estimations increased as stimuli became larger [stimulus effect: $F(6,3231)=670,981, p<.001]$ (Fig. S1G) and did not vary across trials $[F(1,3231)=0.123, p$ $=.726]$. 
US-expectancy ratings - Mixed model with $2^{\text {nd }}$ order polynomial (stimulus and stimulus ${ }^{2}$ ) using stimulus as continuous predictor

\begin{tabular}{|c|c|c|c|c|c|c|}
\hline & Model1 & Model 2 & Model 3 & Model 4 & Model 5 & Model 6 \\
\hline Fixed effects & Par. Est. (SE) & Par. Est. (SE) & Par. Est. (SE) & Par. Est. (SE) & Par. Est. (SE) & Par. Est. (SE) \\
\hline Intercept & $2.693(.255)^{* * *}$ & $2.695(.255)^{* * *}$ & $2.697(.255)^{* * *}$ & $2.689(.256)^{* * *}$ & $2.698(.258)^{* * *}$ & $2.695(.259)^{* * *}$ \\
\hline stim & $1.274(.089)^{* * *}$ & $1.274(.089)^{* * *}$ & $1.273(.088)^{* * *}$ & $1.273(.089)^{* * *}$ & $1.272(.088)^{* * *}$ & $1.266(.089)^{* * *}$ \\
\hline stim $^{2}$ & $-0.154(.011)^{* * *}$ & $-0.154(.011)^{* * *}$ & $-0.154(.011)^{* * *}$ & $-0.154(.011)^{* * *}$ & $-0.154(.011)^{* * *}$ & $-0.153(.011)^{* * *}$ \\
\hline Trial & $-0.009(.006)$ & $-0.010(.007)$ & $-0.010(.007)$ & $-0.010(.007)$ & $-0.010(.007)$ & $-0.010(.007)$ \\
\hline Bias & & $-.008(.017)$ & & & $-.018(.018)$ & $-.010(.018)$ \\
\hline Bias * stim & & .003 (.006-) & & & $.010(.006)$ & $.007(.007)$ \\
\hline Bias * stim² & & $.000(.001)$ & & & $-.001(.001)$ & $-.001(.001)$ \\
\hline$\mu_{u}$ & & & $-.432(.158)^{* * *}$ & & $-.534(.170)$ & \\
\hline$\mu_{u} *$ stim & & & $.254(.057)^{* * *}$ & & $.320(.060)^{* * *}$ & \\
\hline$\mu_{u} * \operatorname{stim}^{2}$ & & & $-.0345(.007)^{* * *}$ & & $-.045(.007)^{* * *}$ & \\
\hline$\sigma_{r}$ & & & & $-.027(.028)$ & & $.031(.030)$ \\
\hline$\sigma_{r} *$ stim & & & & $-.014(.010)$ & & $-.021(.010)$ \\
\hline$\sigma_{r} * \operatorname{stim}^{2}$ & & & & $.002(.001)$ & & $.003(.001)^{*}$ \\
\hline Bias* $\mu_{u}$ & & & & & $-.025(.014)$ & \\
\hline Bias* $\mu_{u} *$ stim & & & & & $.0164(.005)^{* * *}$ & \\
\hline${\text { Bias } * \mu_{u} * \operatorname{stim}^{2}}^{2}$ & & & & & $-.002(.001)^{* * *}$ & \\
\hline Bias* $\sigma_{r}$ & & & & & & $.001(.001)$ \\
\hline Bias* $\sigma_{r} *$ stim & & & & & & $-.001(.001)$ \\
\hline 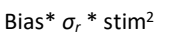 & & & & & & $.0002(.000)^{*}$ \\
\hline
\end{tabular}

Par. Est. $=$ parameter estimate, $\mathrm{SE}=$ standard error, $^{\circ}=p \leq .1,{ }^{*}=p \leq .05, * *=p \leq .01,{ }^{* * *}=p \leq .001$ 
Startle eye blink responses - Mixed model with $2^{\text {nd }}$ order polynomial (stimulus and stimulus ${ }^{2}$ ) using stimulus as continuous predictor

\begin{tabular}{|c|c|c|c|c|c|c|}
\hline & Model1 & Model 2 & Model 3 & Model 4 & Model 5 & Model 6 \\
\hline Fixed effects & Par. Est. (SE) & Par. Est. (SE) & Par. Est. (SE) & Par. Est. (SE) & Par. Est. (SE) & Par. Est. (SE) \\
\hline Intercept & $6.58(1.47)^{* * *}$ & $6.64(1.47)^{* * *}$ & $6.58(1.47)^{* * *}$ & $6.60(1.47)^{* * *}$ & $6.65(1.46)^{* * *}$ & $6.77(1.47)^{* * *}$ \\
\hline stim & $.227(.595)$ & $.223(.593)$ & $.228(.595)$ & $.227(.595)$ & $.229(.593)$ & $.165(.593)$ \\
\hline stim $^{2}$ & $-.014(.073)$ & $-.014(.073)$ & $-.015(.073)$ & $-.015(.073)$ & $-.015(.073)$ & $-.008(.073)$ \\
\hline Trial & $-.141(.018)^{* * *}$ & $-.141(.018)^{* * *}$ & $-.141(.018)^{* * *}$ & $-.141(.018)^{* * *}$ & $-.141(.018)^{* * *}$ & $-.143(.018)^{* * *}$ \\
\hline Bias & & $-.174(.089)^{\circ}$ & & & $-.077(.095)$ & $-.214(.095)^{*}$ \\
\hline Bias * stim & & $.111(.039)^{* *}$ & & & $.083(.042)^{\circ}$ & $.140(.042)^{* * *}$ \\
\hline Bias * stim² $^{2}$ & & $-.012(.005)^{*}$ & & & $-.009(.005)^{\circ}$ & $-.014(.005)^{* *}$ \\
\hline$\mu_{u}$ & & & $-.102(.864)$ & & $.753(.913)$ & \\
\hline$\mu_{u} *$ stim & & & .179 (.389) & & $-.045(.410)$ & \\
\hline$\mu_{u} * \operatorname{stim}^{2}$ & & & $-.015(.047)$ & & $.005(.050)$ & \\
\hline$\sigma_{r}$ & & & & $-.083(.145)$ & & $-.027(.160)$ \\
\hline$\sigma_{r}{ }^{*}$ stim & & & & $.068(.065)$ & & $.025(.071)$ \\
\hline$\sigma_{r} * \operatorname{stim}^{2}$ & & & & $-.006(.008)$ & & $-.001(.008)$ \\
\hline Bias* $\mu_{u}$ & & & & & $.200(.073)^{* *}$ & \\
\hline Bias* $\mu_{u} *$ stim & & & & & $-.056(.033)^{\circ}$ & \\
\hline Bias* $\mu_{u} *$ stim $^{2}$ & & & & & $.005(.003)$ & \\
\hline Bias* $\sigma_{r}$ & & & & & & $.011(.011)$ \\
\hline Bias* $\sigma_{r} *$ stim & & & & & & $-.008(.005)$ \\
\hline Bias $^{*} \sigma_{r} *$ stim $^{2}$ & & & & & & $.001(.001)$ \\
\hline
\end{tabular}

Par. Est. $=$ parameter estimate, $\mathrm{SE}=$ standard error, $^{\circ}=p \leq .1,{ }^{*}=p \leq .05, * *=p \leq .01, * * *=p \leq .001$ 


\section{Effects of STAI-T and PSQ}

No effects of STAI-T or GSQ scores assessed on Day 2 were found on the shape of the US expectancy generalization gradient [STAI-T effect: $F(1,44)<1, p=.902$; STAI-T $\times$ stimulus effect: $F(6,3357)<1, p=.500 ;$ GSQ effect: $F(1,44)<1, p=.537 ;$ GSQ $\times$ stimulus effect: $F(6,3357)<1, p=.457$ ].

No effects of STAI-T or GSQ scores were found on the shape of the gradient for startle eye blink responses apart from a main effect of STAI-T with less potentiation for higher STAI-T scores $(B=-.204, S E=.11)$ [STAI-T effect: $F(1,38)=5.419, p=.025 ;$ STAI-T $\times$ stimulus effect: $F(6,1269)=1.233, p=.286 ;$ GSQ effect: $F(1,38)=1.487, p=.230 ; \mathrm{GSQ} \times$ stimulus effect: $F(6,1270)<1, p=.627$ ]. 